\title{
Induced polarization response of porous media with metallic particles - Part 10: Influence of desiccation
}

\author{
Timothé Tartrat ${ }^{1}$, André Revil ${ }^{1}$, Feras Abdulsamad ${ }^{1}$, Ahmad Ghorbani ${ }^{2}$, Damien Jougnot ${ }^{3}$, \\ Antoine Coperey ${ }^{1}$, Béatrice $\mathrm{Yven}^{4}$, and Rémi de la Vaissière ${ }^{4}$
}

\begin{abstract}
Desiccation influences the complex conductivity of porous media with disseminated metallic particles. We expand the mechanistic model developed in the previous papers of this series to include the effect of saturation upon the complex conductivity of mixtures of mineral grains, pyrite, and pore water. During desiccation, the salt is assumed to be segregated in the liquid pore water; therefore, the conductivity of the pore water increases when saturation decreases. We have performed 14 experiments corresponding to 91 complex conductivity spectra. In these experiments, the saturation of the water phase is changed over time by desiccation. The resulting spectra are fitted by a double Cole-Cole model used as the fitting model. We also developed a mechanistic model in which the chargeability and the relaxation time of the low-frequency polarization are expected to change with saturation in a predictable
\end{abstract}

way. We first characterized the properties of the background material made by an illitic clay material. We determine how the Cole-Cole parameters depend on saturation. The Cole-Cole exponent is essentially independent on saturation. When the chargeability of the mixture is dominated by the presence of pyrite, it becomes independent of the saturation but a small effect on the chargeability is observed at low pyrite contents. The instantaneous conductivity of the background decreases with the saturation in a predictable way. The relaxation time depends on the inverse of the instantaneous conductivity and therefore on saturation. This dependence is well-explained through numerical simulations made with the finite-element method. Finally, we analyze the complex conductivity spectra of two clay-rock core samples from the Callovo-Oxfordian formation in the Paris Basin (France). The spectra are shown as a function of their desiccation and explained thanks to the newly developed model.

\section{INTRODUCTION}

Electrical conductivity tomography has been a key method in hydrogeophysics to monitor dynamic processes occurring in porous media undergoing pore-fluid phase changes (Binley et al., 2015). A natural extension of the electrical conductivity method is spectral-induced polarization (e.g., Bleil, 1948, 1953; Olhoeft, 1985), in which rocks are characterized by a complex-valued conductivity (e. g., Zonge and Wynn, 1975). The real part of this conductivity (the so-called in-phase conductivity) is due to the conduction of the current and characterizes the electromigration of the charge carriers (cations and anions in the pore water and electrons and p-holes in semiconductors) in response to the application of an external electrical field. This conductivity characterizes the ability of rocks to conduct an electrical current under the effect of an imposed electrical field. The imaginary part (the so-called quadrature conductivity) characterizes the polarization of the material, i.e., its ability to store reversibly electrical charges under the effect of the same applied electrical field (Marshall and Madden, 1959; Wait, 1959). This reversible storage of electrical charges is due to the polarization of the electrical double layer around the insulating grains of the material (Dias, 1972, 2000), especially around clay minerals (Lesmes and

\footnotetext{
Manuscript received by the Editor 1 February 2019; revised manuscript received 9 June 2019; published ahead of production 03 July 2019 ; published online 16 September 2019.

${ }^{1}$ Université Grenoble Alpes, Université Savoie Mont Blanc, CNRS, IRD, IFSTTAR, ISTerre, Grenoble 38000, France. E-mail: tartrattimothe@gmail.com; andre.revil@univ-smb.fr (corresponding author); feras.abdul-samad@univ-smb.fr; antoine.coperey@gmail.com.

${ }^{2}$ Yazd University, Department of Mining and Metallurgical Engineering, Yazd, Iran. E-mail: aghorbani@yazd.ac.ir.

${ }^{3}$ Sorbonne Université, CNRS, EPHE, UMR 7619 Metis, 4 Place Jussieu, Paris 75005, France. E-mail: damien.jougnot@upmc.fr.

${ }^{4}$ ANDRA, R\&D Division, 1-7 Rue Jean Monnet, Parc de la Croix-Blanche, Châtenay-Malabry Cedex 92298, France. E-mail: beatrice.yven@andra.fr; remi. delavaissiere@andra.fr.
}

(C) 2019 Society of Exploration Geophysicists. All rights reserved. 
Frye, 2001; Revil et al., 2017b, 2017c) and the accumulation of charges at the (external or internal) boundaries of semi-conductors such as pyrite (Pelton et al., 1978; Wong, 1979; Revil et al., 2015a, 2015b; Mao and Revil, 2016; Mao et al., 2016).

Our previous works (Revil et al., 2015a, 2015b, 2017a; Mao and Revil, 2016; Mao et al., 2016) were performed in saturated conditions, and a fundamental understanding of the polarization of pyritebearing rocks in unsaturated conditions is still missing. However, such knowledge is important, for instance, to interpret well-log data in oil-bearing sandstones containing pyrite. There are other applications of the spectral-induced polarization method media in such partially saturated media. For instance, induced polarization can be used to monitor the excavation damaged zone (EDZ) that forms around galleries, in clay-rich formations, used for long-term repository of (radioactive) wastes. The excavation of underground openings induces fracture networks in the surrounding rock. This fracture network is determined by basic mechanical properties and excavation geometry parameters versus in situ stress and bedding parameters (Volckaert et al., 2004). In the Meuse/Haute-Marne Underground Research Laboratory, the French national agency for radioactive waste management (ANDRA) has developed an extensive research program to understand the mechanisms and the possible pattern and extent of induced fracture zones. This URL is built in the CallovoOxfordian (COx) clayrock that contains small proportions of pyrite. Armand et al. (2014) describe the methods used and the excavationinduced fracture network for different excavation and support techniques. During the operating phase of the repository, tunnel ventilation will lead to the desiccation of the COx clayrock along the fracture network. Zhang et al. (2019) investigate the effect of desiccation on the complex conductivity of sandstones, but a fundamental model of spectral-induced polarization in pyrite-rich materials is still missing.

Although electrical resistivity has been applied to image the EDZ (Kiewer, 2000; Kruschwitz, 2002; Yaramanci and Kiewer, 2004), there is no work to date to connect induced polarization parameters to saturation and pyrite content with the exceptions of Kruschwitz and Yaramanci (2004), Jougnot et al. (2010), and Okay et al. (2013). In addition, probing how saturation may influence the complex conductivity of pyrite-bearing rocks is important to further test the theory developed in the previous papers of our series. The approach developed below is also of crucial importance in mining geophysics

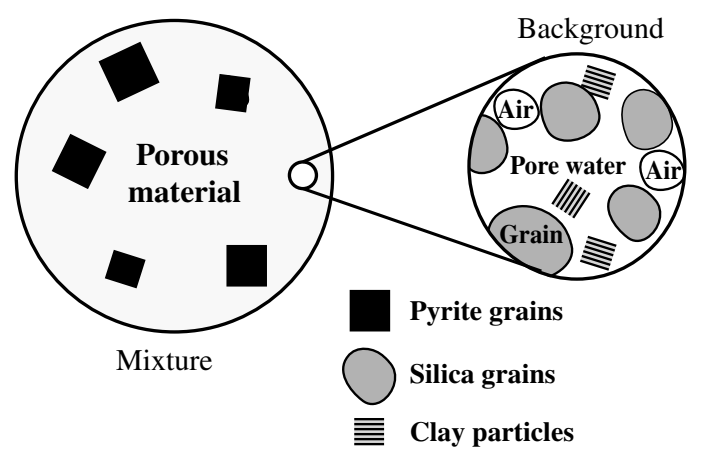

Figure 1. Sketch of the complex background clay material and the mixture between the background (an illitic clay in our case) and the metallic particles (pyrite grains in our case). The background material can be partially saturated with a partial saturation $s_{w}$. In the case of desiccation, the salinity of the pore water increases when the saturation decreases. to locate shallow ores in the vadose zone especially with the development of airborne time-domain electromagnetic methods (e.g., Kratzer and Macnae, 2012; Kwan et al., 2015; Kaminski and Viezzoli, 2017).

The present paper is divided into four sections. In the first section, we expand our model to unsaturated conditions and for desiccation and we developed a so-called physical or mechanistic model. We make predictions regarding the dependence of the Cole-Cole parameters used to represent complex conductivity spectra with the saturation. Some of these dependencies are also checked through some finite-element modeling of the polarization of a single cube of pyrite in a background (porous) material undergoing desiccation. Then, we present the experimental setup, the core samples, and the experiments that are performed in the context of this paper. The core samples are made of mixes of illite and pyrite. We also use two COx core samples undergoing desiccation. Understanding these data is important to monitor the EDZ that forms around galleries of the Meuse/HauteMarne Underground Research Laboratory for the long-term repository of radioactive wastes. A comparison between the predictions of the semiempirical model and the experimental data is provided in the following section. Finally, we discuss how these results can be applied in understanding the signature of the desiccation of the COx formation upon their complex conductivity spectra, which can be
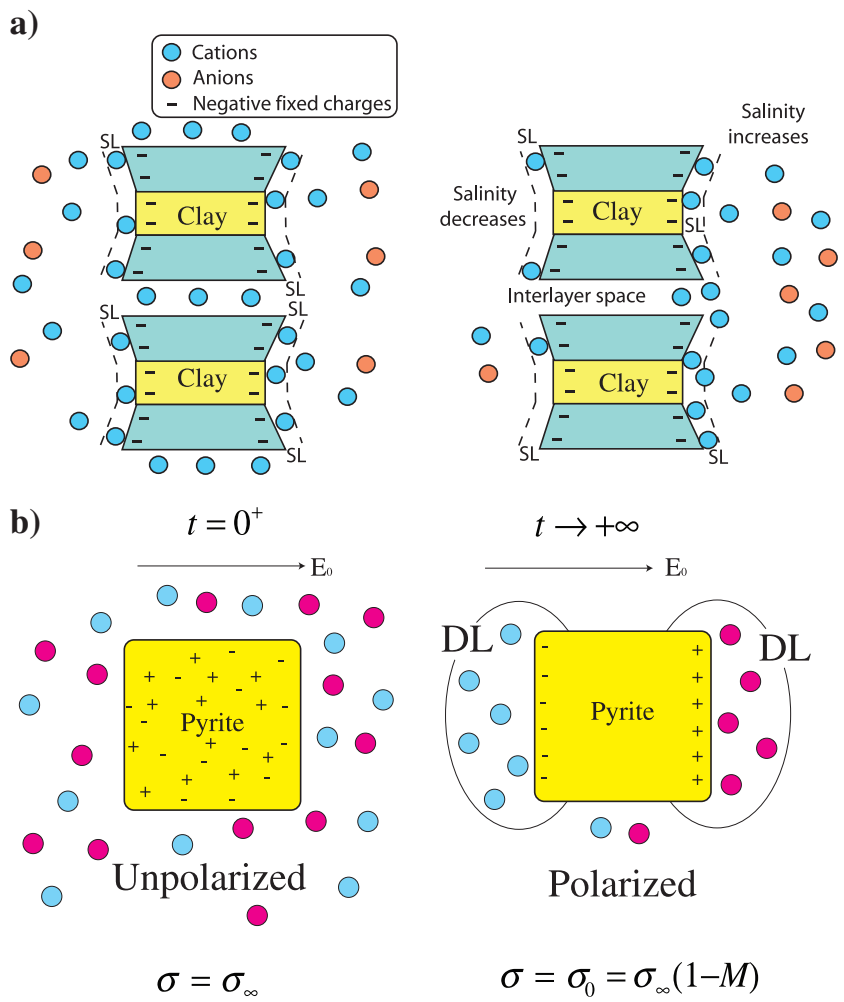

Figure 2. Sketch of the polarization of the metallic and nonmetallic grains. (a) The nonmetallic grains such as clays possess an electrical double layer coated to their surface. Under the influence of an external electrical field $\mathbf{E}_{0}$, this electrical double layer polarizes and provides a dipole moment to the grain. The main mechanism of polarization is the Stern layer (SL) polarization. (b) Polarization of a pyrite cube. The charges carriers inside the grain (electrons and p-holes) polarize the grain. A second polarization component is associated with field-induced diffuse layers (DLs). The first column defines the instantaneous conductivity, whereas the second column defines the DC conductivity. 
fully characterized by a double Cole-Cole parametric model (the fitting model).

\section{THEORY}

In the absence of metallic particles, the polarization of colloidal particles such as clays can find its origin in the polarization of the inner part of their electrical double layer called the Stern layer (e.g., Vinegar and Waxman, 1984; Rosen and Saville, 1991; Rosen et al., 1993; Razilov and Dukhin, 1995; Revil and Florsch, 2010). Therefore, we start here by introducing the principle of the electrical double layer model around the clay minerals.

The surface of clays is generally negatively charged because of isomorphic substitutions in the crystalline framework plus amphoteric reactions on the edges of the crystals. This surface charge

Table 1. Characteristics of the background material made of an illitic clay.

\begin{tabular}{lc}
\hline Property & Value \\
\hline CEC & $9.744 \mathrm{meq} / 100 \mathrm{~g}$ \\
& $\left(9401.5 \mathrm{C} \mathrm{kg}^{-1}\right)$ \\
Porosity $\varphi$ & 0.65 \\
Formation factor $F$ & 2.08 \\
Surface conductivity $\sigma_{s}$ & $2 \times 10^{-2} \mathrm{~S} \mathrm{~m}^{-1}$ \\
Quadrature conductivity $\sigma^{\prime \prime}$ & $2 \times 10^{-4} \mathrm{~S} \mathrm{~m}^{-1}$ \\
$(1 \mathrm{~Hz})$ & \\
\hline
\end{tabular}

Note: $\mathrm{CEC}$ in meq/100 $\mathrm{g}\left(=963.20 \mathrm{Ckg}^{-1}\right)$. The porosity was computed thanks to mass of the saturated material and its volume. Formation factor and surface conductivity were determined from the data shown in Figure 4.

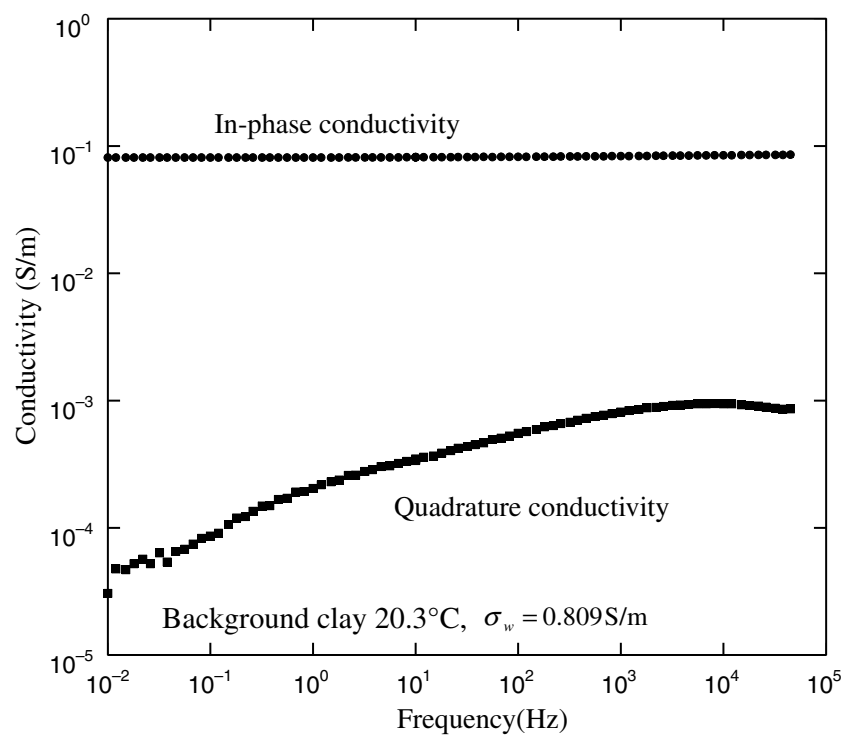

Figure 3. Complex conductivity (in-phase and quadrature components) of the background clay material. The high polarizability of the background material is consistent with its high CEC (see Table 1). The polarization reaches its peak between 1 and $10 \mathrm{kHz}$. The associated relaxation time is associated with the small size of the clay particles (no pyrite here). attracts counterions (e.g., $\mathrm{Na}^{+}$) and repels the co-ions (e.g., $\mathrm{Cl}^{-}$), forming an electrical double layer around the minerals in the absence of an external electrical field. This electrical double layer is composed of the Stern layer and the diffuse layers. When an electric field is applied to such porous material, the positive charges of the Stern layer migrate to accumulate on one side at the surface of the grains. This lets a fixed (structural) negative charge behind that is not locally compensated anymore. This migration of positive and negative charges in the electrolyte and Stern layer confers a dipole moment to the grains. The counterions of the Stern layer essentially move tangentially along the grain surface under the gradient of their
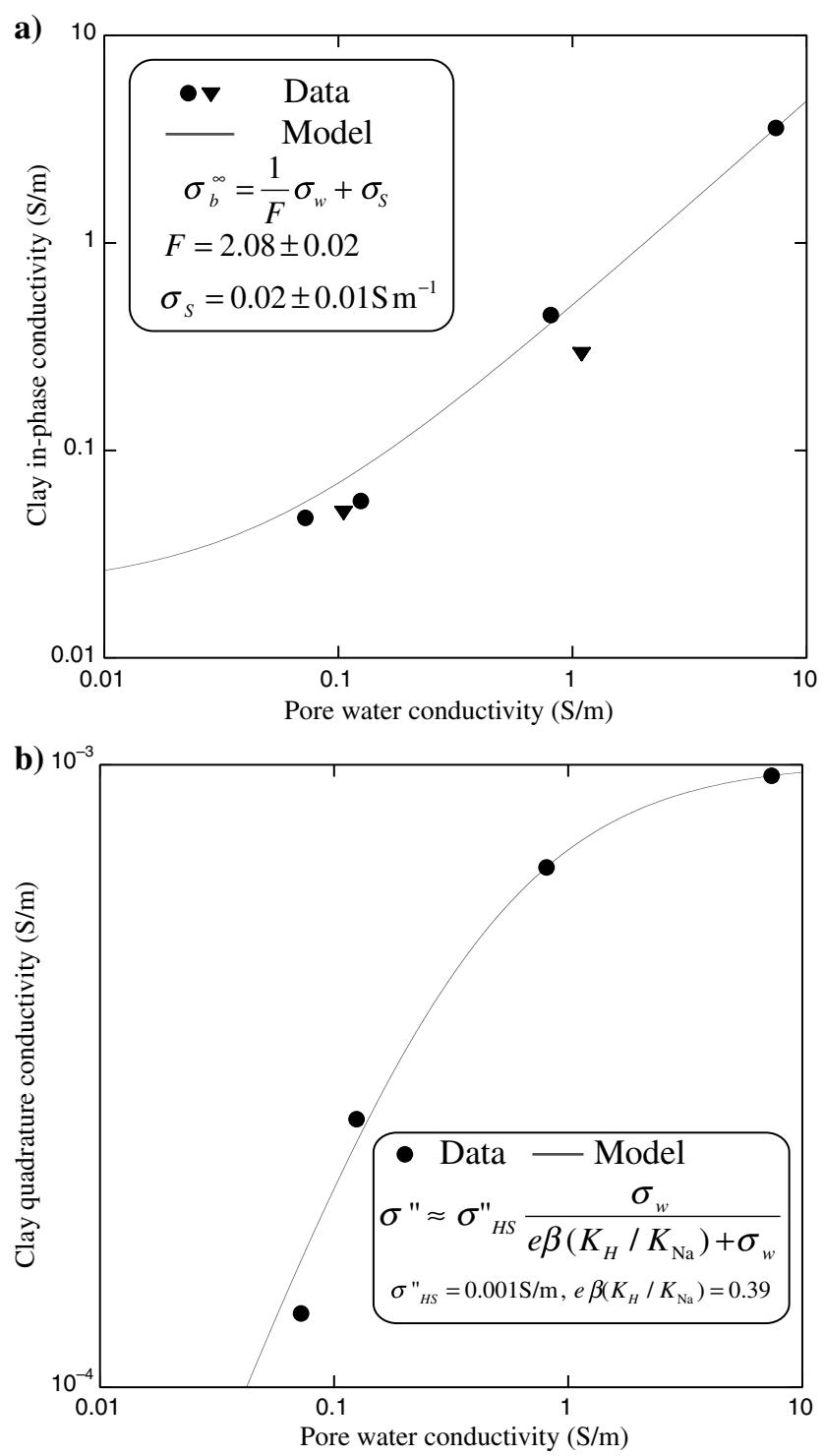

Figure 4. Complex conductivity of the background material. (a) Inphase conductivity at $1 \mathrm{~Hz}$. Conductivity of the background clayey material as a function of the conductivity of the pore water at $25^{\circ} \mathrm{C}$. The plain line corresponds to the fit of the data with a linear conductivity model (here in a log-log space) used to determine the formation factor and the surface conductivity $\sigma_{S}$ of the background material here determined at $1 \mathrm{~Hz}$. The inverted triangle and filled circles are from experiments 1 and 8. (b) Quadrature conductivity versus pore water conductivity at $1 \mathrm{~Hz}$. 
electrochemical potentials (i.e., through electromigration and diffusion in their surface concentration gradients). The counterions can still have the possibility to leave the Stern layer, so the grains are considered as leaking capacitances and not perfect capacitances. This is due to sorption/desorption phenomena as pointed out by Rosen and Saville (1991) and Rosen et al. (1993). These phenomena are at the origin of the induced polarization of the background in our experiment, and are described by Rosen and Saville (1991),

Table 2. Desiccation experiments (experiments 1-14).

\begin{tabular}{lccc}
\hline Experiment & $\varphi_{m}(\%)$ & $\sigma_{w}\left(\mathrm{~S} \mathrm{~m}^{-1}\right)$ & $s_{w}$ Saturation range \\
\hline Experiment 1 & 0 & 0.115 & $1,0.98,0.84,0.69,0.52,0.34$ \\
Experiment 2 & 0.11 & 0.115 & $1,0.99,0.88,0.75,0.61,0.45$ \\
Experiment 3 & 0.29 & 0.115 & $1,1,0.89,0.77,0.65,0.51$ \\
Experiment 4 & 0.81 & 0.115 & $1,0.99,0.89,0.75,0.63,0.49$ \\
Experiment 5 & 2.13 & 0.115 & $1,0.99,0.89,0.73,0.59,0.44$ \\
Experiment 6 & 5.87 & 0.115 & $1,0.99,0.87,0.70,0.55,0.40$ \\
Experiment 7 & 15.82 & 0.115 & $1,0.99,0.85,0.66,0.50,0.32$ \\
Experiment 8 & 0 & 1.081 & $1,0.88,0.74,0.56,0.54,0.38,0.24$ \\
Experiment 9 & 0.11 & 1.081 & $1,0.90,0.77,0.62,0.61,0.49,0.36$ \\
Experiment 10 & 0.30 & 1.081 & $1,0.90,0.78,0.63,0.62,0.49,0.36$ \\
Experiment 11 & 0.89 & 1.081 & $1,0.86,0.72,0.54,0.54,0.37,0.24$ \\
Experiment 12 & 2.13 & 1.081 & $1,0.86,0.73,0.57,0.56,0.42,0.33$ \\
Experiment 13 & 5.79 & 1.081 & $1,0.86,0.72,0.52,0.52,0.35,0.21$ \\
Experiment 14 & 13.00 & 1.081 & $1,0.86,0.71,0.52,0.52,0.35,0.21$ \\
\hline
\end{tabular}

Note: The quantity $\phi_{m}$ denotes the volume fraction of pyrite. A total of 91 spectra are covered by these experiments. Saturation was determined with equation 15 . The pore water conductivity is the initial pore water conductivity.

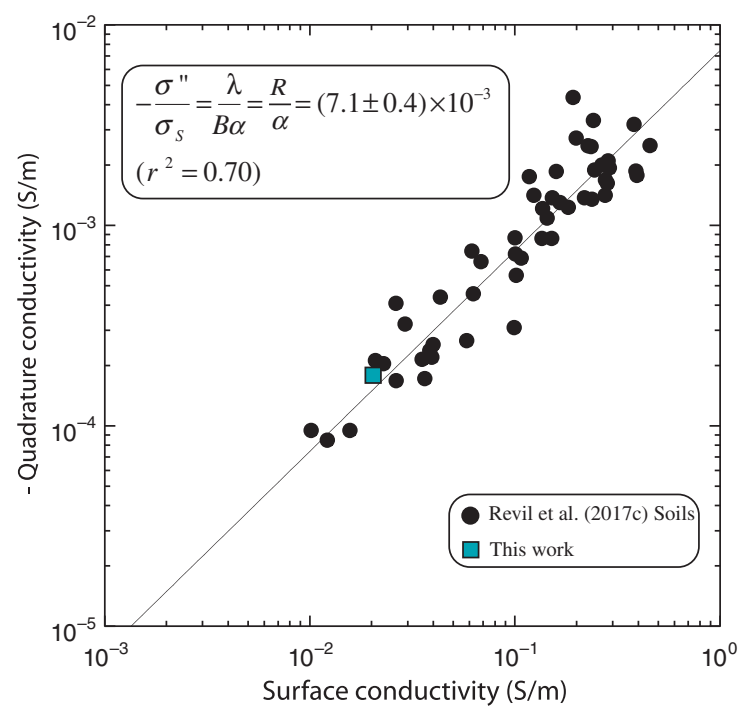

Figure 5. Quadrature conductivity $(1 \mathrm{~Hz})$ versus surface conductivity for porous clayey materials without metallic particles. Filled circles: data from the study of Revil et al. (2017c, soils) for a pore water conductivity $(\mathrm{NaCl})$ of $0.03 \mathrm{~S} \mathrm{~m}^{-1}$. Present data at the pore water conductivity of $0.1 \mathrm{~S} \mathrm{~m}^{-1}$.
Rosen et al. (1993), Revil and Florsch (2010), and recently Hou et al. (2018).

Now, we consider the mixture of a porous background material (as described above) and dispersed metallic particles such as shown in Figure 1. In this type of mixture, the clay particles and the metallic grains are polarizable with distinct polarization mechanisms (Figure 2). Immediately after the application of an (external/applied) electrical field, all the charges at the surface of the metallic and nonmetallic grains are put in motion because their velocity is controlled by the gradient of the electrochemical potential of the charge carriers (Figure 2). This state corresponds to the high-frequency limit with the maximum conductivity written as $\sigma_{\infty}$. On the contrary, when a direct electric current has been applied for a long time, the cations in the Stern layer are held back on one side of the grain and are not available anymore for the conduction of the current. This corresponds to the low-frequency limit of the complex conductivity function also called the direct current (DC) conductivity $\sigma_{0}$ (Figure 2). The chargeability (dimensionless) is defined as the following ratio of conductivity:

$$
M=\frac{\sigma_{\infty}-\sigma_{0}}{\sigma_{\infty}}
$$

where $\sigma_{\infty}$ and $\sigma_{0}\left(\mathrm{~S} \mathrm{~m}^{-1}\right)$ define the instantaneous electrical conductivity and the DC electrical conductivity of the mixture between the metallic particles and the background material. In the presence of metallic particles mixed with nonmetallic grains (e.g., silica grains and clays), Revil et al. (2015a, 2015b) develop a model based on a linearized version of the self-consistent Maxwell-ClausiusMossotti approximation. In this model, the chargeability of the mixture is given by

$$
M=\frac{9}{2} \varphi_{m}+M_{b},
$$

where $\varphi_{m}$ (dimensionless) denotes the volume fraction of metallic particles in the mixture and $M_{b}$ (dimensionless) denotes the chargeability of the background material (which is the porous mixture around the metallic particles).

To go further, we need to describe how the chargeability of the background material (dimensionless)

$$
M_{b}=\frac{\sigma_{b}^{\infty}-\sigma_{b}^{0}}{\sigma_{b}^{\infty}}
$$

may depend on saturation. In equation $3, \sigma_{b}^{\infty}$ and $\sigma_{b}^{0}$ denote the instantaneous conductivity and the DC conductivity of the background material, respectively. Each of these conductivities is the sum of two contributions. The first contribution comes from the conduction in the bulk pore water, and it is associated with the pore water conductivity $\sigma_{w}\left(\mathrm{~S} \mathrm{~m}^{-1}\right)$. The second contribution, called surface conductivity, can be related to the cation exchange capacity of the material (CEC, $\mathrm{C} \mathrm{kg}^{-1}$ ) (Waxman and Smits, 1968; Lima and Sharma, 1990). The expressions of the instantaneous and DC 
conductivities of the background material are given by (Revil et al., 2017c)

$$
\begin{gathered}
\sigma_{b}^{\infty}=s_{w}^{n} \frac{1}{F} \sigma_{w}+s_{w}^{n-1}\left(\frac{1}{F \phi}\right) \rho_{g} B \mathrm{CEC}, \\
\sigma_{b}^{0}=s_{w}^{n} \frac{1}{F} \sigma_{w}+s_{w}^{n-1}\left(\frac{1}{F \phi}\right) \rho_{g}(B-\lambda) \mathrm{CEC},
\end{gathered}
$$

where $F$ (dimensionless) denotes the formation factor related to the connected porosity by Archie's law $F=\phi^{-m}$ (Archie, 1942), $\phi$ (dimensionless) is the porosity, and $m$ (dimensionless) denotes the cementation or porosity exponent. The term $\rho_{g}$ denotes the grain density (typically $2650 \mathrm{~kg} \mathrm{~m}^{-3}$ ), $\sigma_{w}$ denotes the pore water conductivity $\left(\mathrm{S} \mathrm{m}^{-1}\right), s_{w}$ (dimensionless) denotes the saturation, and $n$ (dimensionless) is the saturation exponent of the Archie model (most of time, this exponent is approximately 2 like $m$ ). The mobility $B$ $\left(\mathrm{m}^{2} \mathrm{~s}^{-1} \mathrm{~V}^{-1}\right)$ denotes the apparent mobility of the counterions for the surface conduction, and $\lambda\left(\mathrm{m}^{2} \mathrm{~s}^{-1} \mathrm{~V}^{-1}\right)$ denotes the apparent mobility of the counterions for the polarization associated with the quadrature conductivity (see Revil et al., 2017c). The last terms of equations 4 and 5 correspond to the so-called surface conductivity with the instantaneous and DC surface conductivity written as $\sigma_{S}^{\infty}=$ $s_{w}^{n-1} \rho_{g} B \mathrm{CEC} / F \phi$ and $\sigma_{S}^{0}=s_{w}^{n-1} \rho_{g}(B-\lambda) \mathrm{CEC} / F \phi$, respectively.

A dimensionless number $R$ is also introduced by $R=\lambda / B$ (for further explanations, see Revil et al., 2017b, 2017c). From
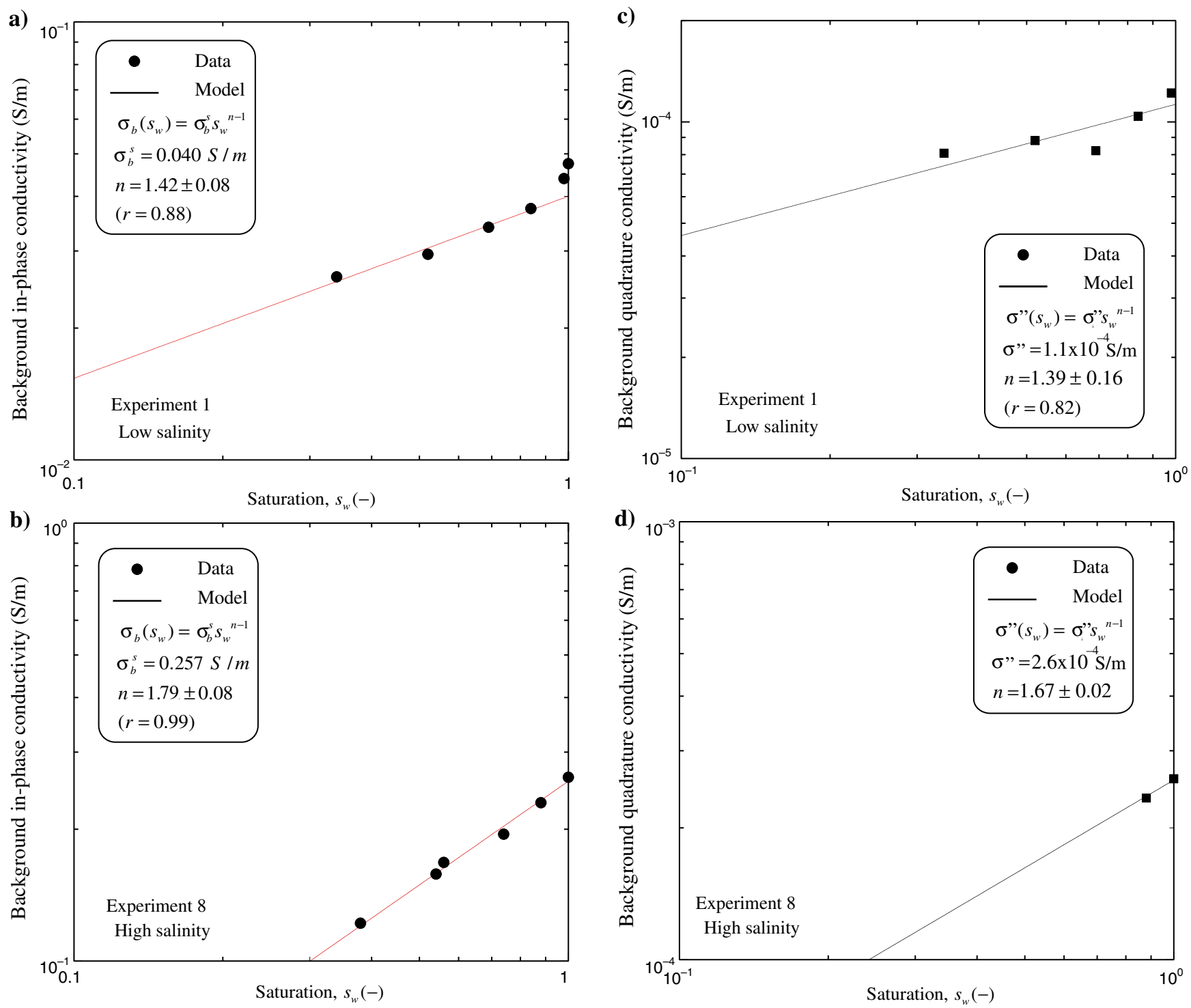

Figure 6. Background conductivity versus saturation (test of the second Archie's law). (a) In-phase conductivity (at $1 \mathrm{~Hz}$ ) for a pore water conductivity $\sigma_{w}$ of $0.115 \mathrm{~S} \mathrm{~m}^{-1}$ of the background clayey material (experiment 1 , no pyrite). (b) In-phase conductivity (at $1 \mathrm{~Hz}$ ) for a pore water conductivity of $1.081 \mathrm{~S} \mathrm{~m}^{-1}$ of the background clayey material (experiment 8, no pyrite). (c) Quadrature conductivity (at $1 \mathrm{~Hz}$ ) for a pore water conductivity $\sigma_{w}$ of $0.115 \mathrm{~S} \mathrm{~m}^{-1}$ (experiment 1 , no pyrite). (d) Quadrature conductivity (at $1 \mathrm{~Hz}$ ) for a pore water conductivity of $1.081 \mathrm{~S} \mathrm{~m}^{-1}$ (experiment 8 , no pyrite, only the data with small standard deviations are used). 
our previous studies (e.g., Ghorbani et al., 2018), we have $B\left(\mathrm{Na}^{+}, 25^{\circ} \mathrm{C}\right)=3.1 \pm 0.3 \times 10^{-9} \mathrm{~m}^{-2} \mathrm{~s}^{-1} \mathrm{~V}^{-1}$ and $\lambda\left(\mathrm{Na}^{+}, 25^{\circ} \mathrm{C}\right)=$ $3.0 \pm 0.7 \times 10^{-10} \mathrm{~m}^{-2} \mathrm{~s}^{-1} \mathrm{~V}^{-1}$, and the dimensionless number $R$ is approximately $0.09 \pm 0.02$ (independent of saturation). This dimensionless number can be used to connect surface conductivity in metal-free porous media to quadrature conductivity and/or normalized chargeability (Weller et al., 2013). The background chargeability being defined in equation 3 , we have with the help of equations 4 and 5:

$$
M_{b}=\frac{\rho_{g} \lambda \mathrm{CEC}}{\phi s_{w} \sigma_{w}+\rho_{g} B \mathrm{CEC}} .
$$

We can easily show that at low salinity $\left(\sigma_{w} \ll \rho_{g} B C E C / \phi s_{w}\right)$, we have $M_{b}=R$. However, equation 6 considers that there is no
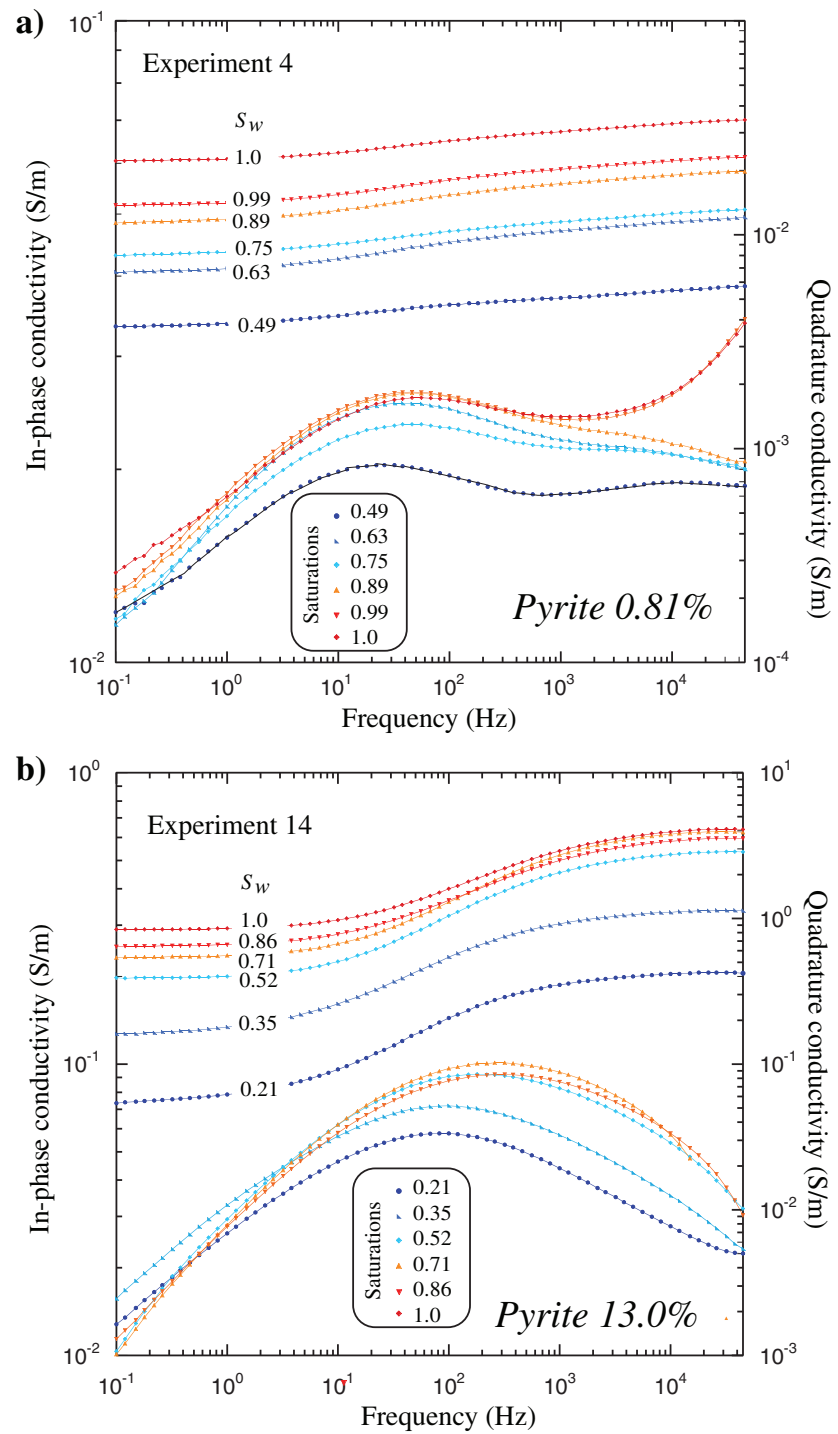

Figure 7. Complex conductivity (in-phase and quadrature components) spectra. (a) For experiment 4 (low pyrite content). The peak frequency decreases to lower frequencies when the saturation decreases. (b) For experiment 14 (high pyrite content). The peak frequency decreases to lower frequencies when the saturation decreases. change in salinity during the change of saturation. In the case in which a porous material is undergoing desiccation, its pore-water conductivity increases due to the increase of the salinity in the liquid water; therefore, $\sigma_{w}=\sigma_{w}^{s} / s_{w}$, where $\sigma_{w}^{s}$ denotes the conductivity of the pore water at $100 \%$ water saturation $\left(s_{w}=1\right)$. In that case, the background chargeability is independent of the saturation because

$$
\begin{gathered}
\sigma_{b}^{\infty}=s_{w}^{n-1}\left[\frac{1}{F} \sigma_{w}^{s}+\left(\frac{1}{F \phi}\right) \rho_{g} B \mathrm{CEC}\right], \\
\sigma_{b}^{0}=s_{w}^{n-1}\left[\frac{1}{F} \sigma_{w}^{s}+\left(\frac{1}{F \phi}\right) \rho_{g}(B-\lambda) \mathrm{CEC}\right],
\end{gathered}
$$

$$
M_{b}=\frac{\rho_{g} \lambda \mathrm{CEC}}{\phi \sigma_{w}^{s}+\rho_{g} B \mathrm{CEC}} .
$$

Therefore, during desiccation, the background chargeability does not explicitly depend on saturation. That said, the increase of salinity may play a certain role in the parameters involved in equation 9 as explained below and in Niu et al. (2016). Such a change is associated with the density of the counterions in the Stern layer and the increase of this density (and therefore the associated polarization) when the salinity increases.

We can now connect the chargeability to the complex conductivity of the mixture between the background and the metallic particles. We write the complex conductivity of this mixture as $\sigma *=\sigma^{\prime}+i \sigma^{\prime \prime}$, where $\sigma^{\prime}$ and $\sigma^{\prime \prime}\left(\mathrm{S} \mathrm{m}^{-1}\right)$ stand for the in-phase and quadrature components, respectively. Considering a Cole-Cole parametric model (Cole and Cole, 1941), we have

$$
\sigma_{\infty}=\sigma_{b}^{\infty}\left(1+3 \varphi_{m}\right)
$$

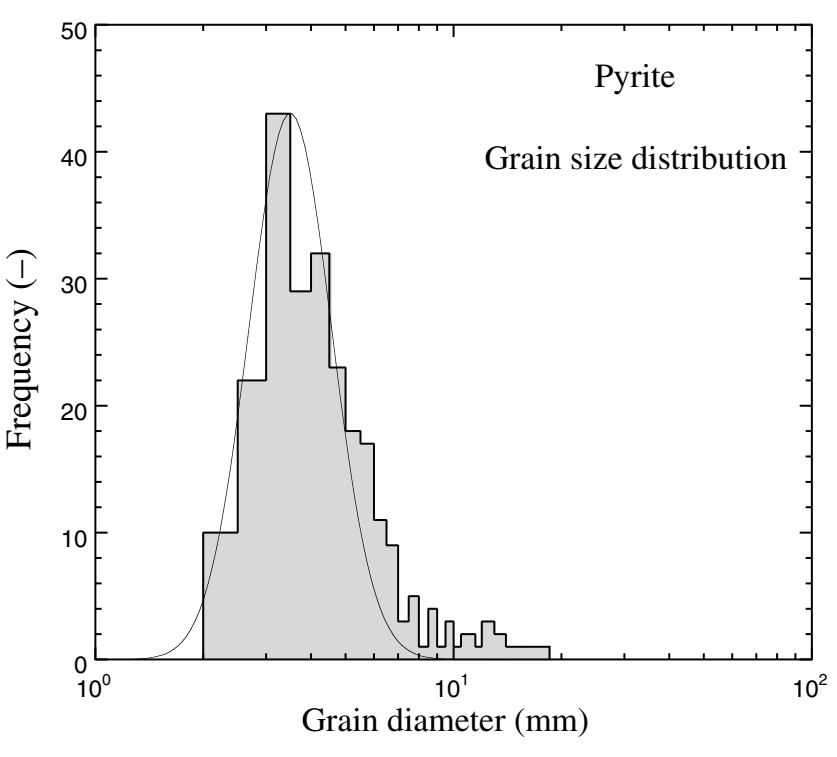

Figure 8. Distribution of the grain sizes for pyrite. Note that the distribution is approximately a log normal distribution (plain line) with a mean grain size of $4.5 \pm 2.6 \mathrm{~mm}$. 

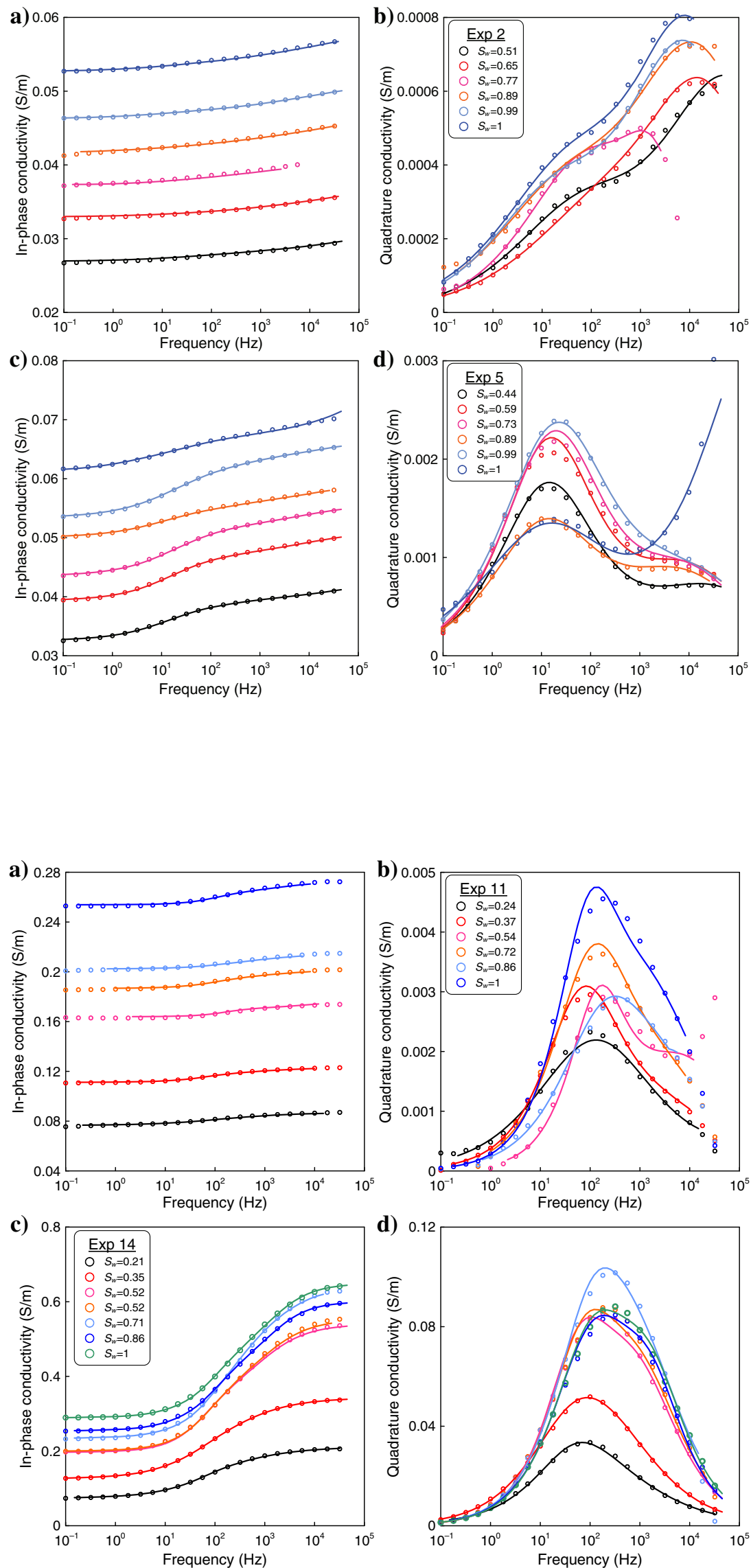

Figure 9. Fit with the double Cole-Cole complex conductivity model (the plain lines) of the measured spectra (the symbols). (a and b) In-phase and quadrature conductivities for experiment 2 (pyrite content $0.11 \%$ ). (c and d) In-phase and quadrature conductivities for experiment 5 (pyrite content $2.13 \%$ ).

Figure 10. Fit with the double Cole-Cole complex conductivity model (the plain lines) of the measured spectra (the symbols). (a and b) In-phase and quadrature conductivities for experiment 11 (volumetric metallic content $0.89 \%$ ). (c and d) In-phase and quadrature conductivities for experiment 14 (volumetric metallic content 13\%). 
where $M$ is defined in equation 2 . Note that this Cole-Cole model is quite different with respect to the Cole-Cole model proposed by Pelton et al. (1978) and Johnson (1984) (see the details in Tarasov and Titov [2013], who explicitly compare different Cole-Cole models and connect their Cole-Cole parameters). The instantaneous conductivity of the mixture shown in Figure 1 is related to the instantaneous conductivity of the background by (Revil et al., 2015a, 2015b)

$$
\sigma_{\infty}=\sigma_{b}^{\infty}\left(1+3 \varphi_{m}\right) .
$$

The last parameter to define in equation 10 is the Cole-Cole time constant that is given by (Revil et al., 2018a)

$$
\tau_{0} \approx \frac{a^{2} e^{2} C_{m}}{k_{b} T \sigma_{b}^{\infty}},
$$
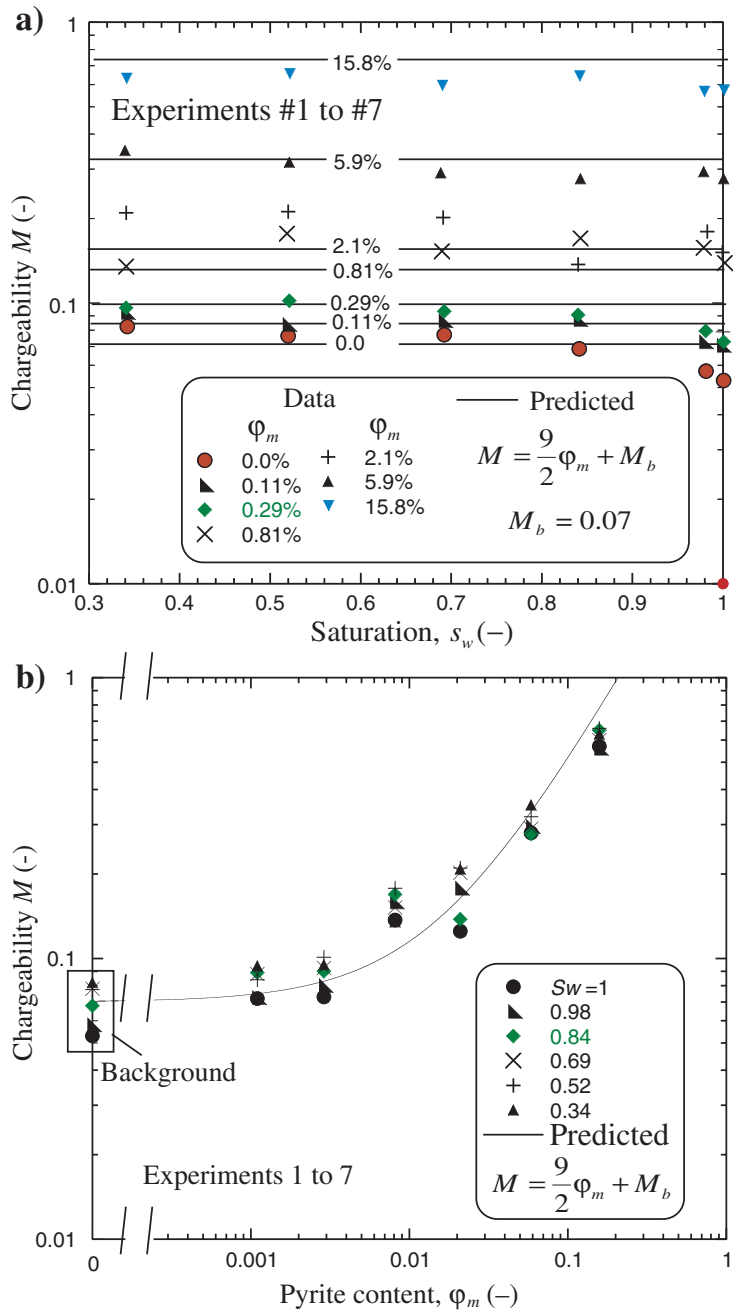

Figure 11. Chargeability $M$ versus saturation and pyrite content. (a) Chargeability as a function of the saturation for an initial pore water conductivity $\sigma_{w}$ of $0.115 \mathrm{~S} \mathrm{~m}^{-1}$ and different volumetric contents $\varphi_{m}$ of pyrite. The plain lines represent the predictions of the model. (b) Chargeability as a function of the volume fraction of pyrite for an initial pore water conductivity of $0.115 \mathrm{~S} \mathrm{~m}^{-1}$. The fitted background value for the chargeability is $M_{b}=0.07$. where $a$ denotes the diameter of the metallic particle (m), $C_{m}$ denotes the concentration of the charge carriers in the solid metallic particle $\left(\mathrm{m}^{-3}\right), e$ denotes the elementary charge $\left(1.6 \times 10^{-19} \mathrm{C}\right), k_{b}$

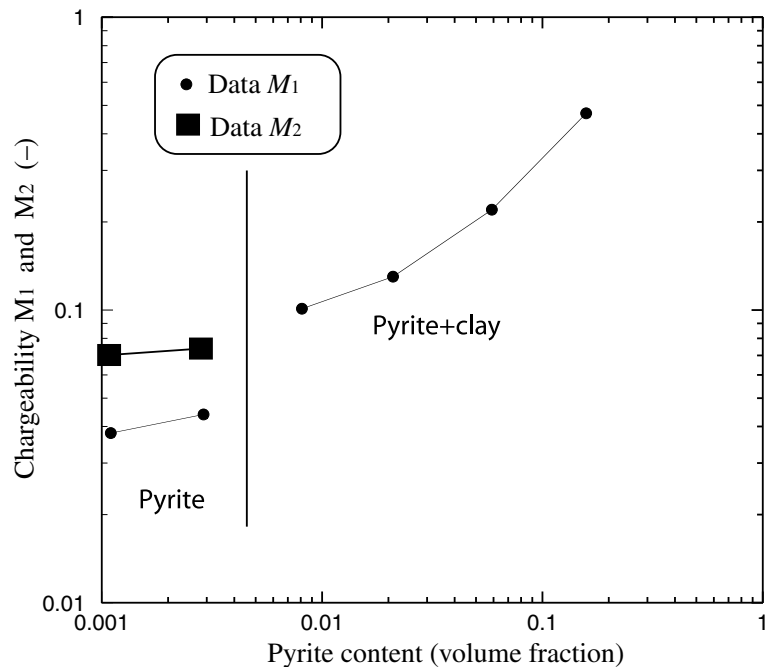

Figure 12. Chargeability contribution $M_{1}$ determined from the fitting model described in Appendix A. We see that at low pyrite contents, the component $M_{1}$ describes the pyrite contribution, whereas at higher pyrite contents (above $0.5 \%$ ), the component $M_{1}$ describes the pyrite and clay contributions. The chargeability $M 2$ in the section of low pyrite content (only clay) corresponds to the chargeability associated with the clay only.

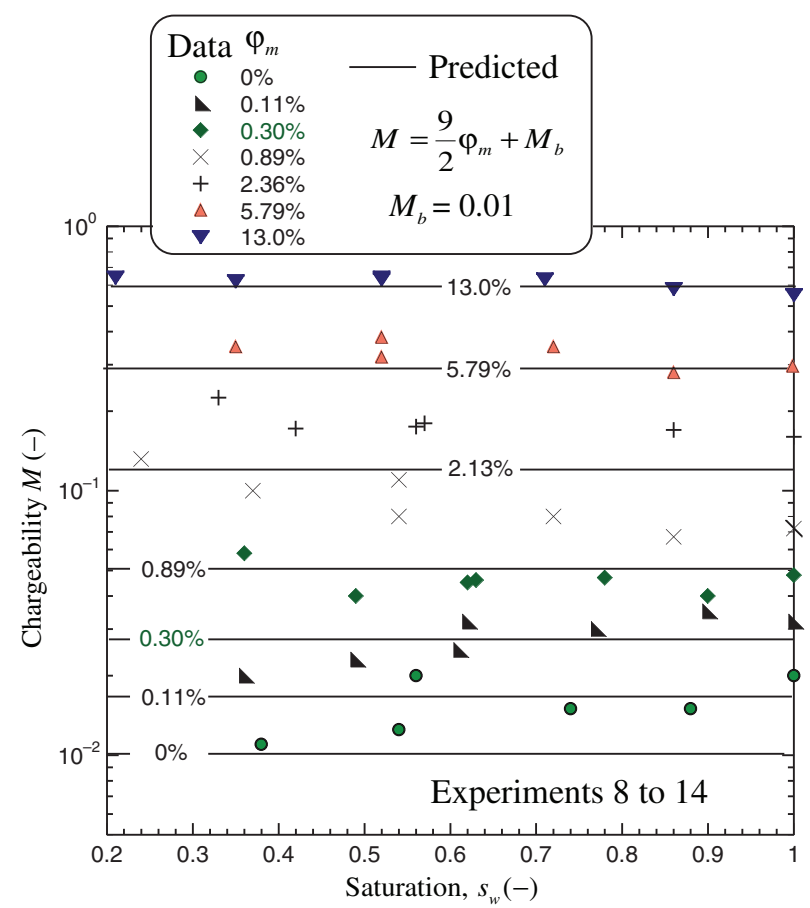

Figure 13. Chargeability as a function of the saturation $s_{w}$ for an initial pore water conductivity of $1.081 \mathrm{~S} \mathrm{~m}^{-1}$ and different volumetric content of pyrite (experiments 8-14). The plain lines represent the predictions of the model. The values given on the graph denote the volumetric contents in pyrite. The chargeability is here defined from the conductivity at $0.1 \mathrm{~Hz}$ and $45 \mathrm{kHz}$. The chargeability of the background material is close to 0.01 . 


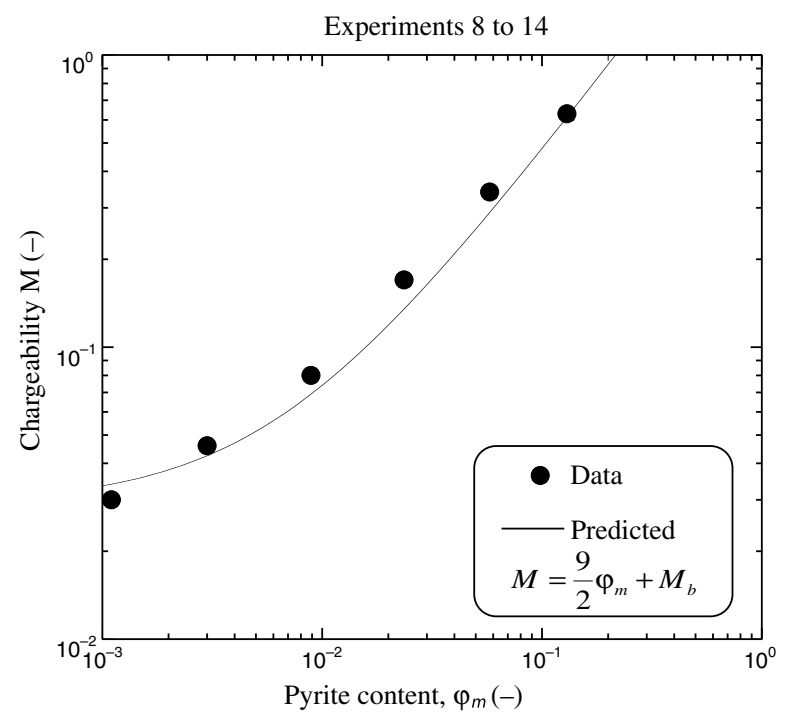

Figure 14. Chargeability as a function of the volumetric contents of pyrite for an initial pore water conductivity of $1.081 \mathrm{~S} \mathrm{~m}^{-1}$ (at each pyrite content, we took an average of the values obtained at the different saturations). The plain line represents the predictions of the model with a background chargeability of $2.9 \times 10^{-2}$, which is slightly different from the value used in Figure 13 (0.01). We observe that the background chargeability is smaller due to the higher salinity of the pore water. Each black circle is obtained by taking the median of all the values obtained at different saturations for the same value of the pyrite content. The coefficient of determination $r^{2}=0.95$.

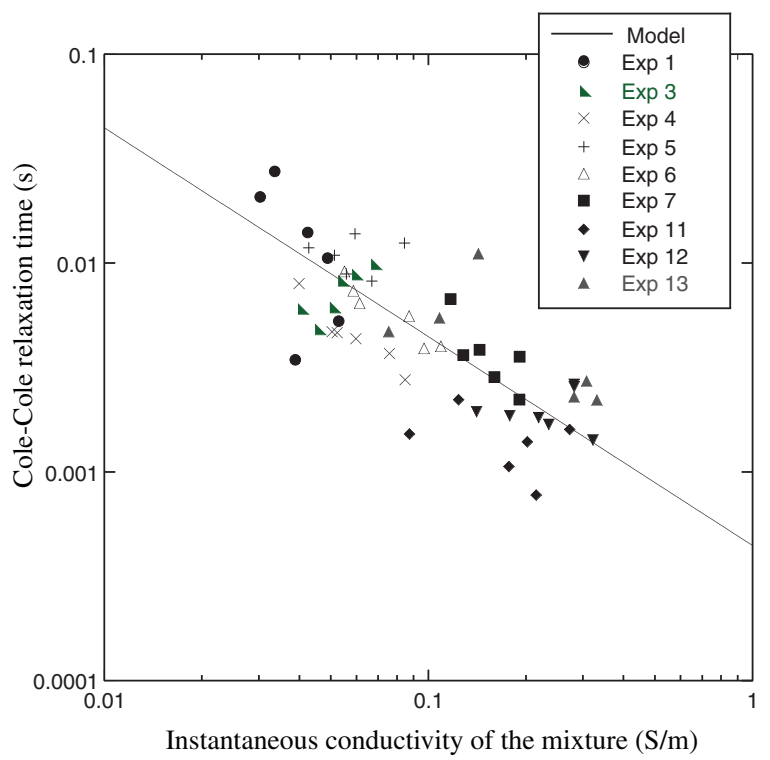

Figure 15. Cole-Cole relaxation time $\tau_{1}$ versus the instantaneous conductivity of the mixture. We see that the two quantities are inversely proportional to each other (the plain line). Coefficient of determination $r^{2}=0.888$. The data of experiments $2,9,10$, and 14 have not been added to the graph because of higher uncertainty in the determination of the time constants for these experiments. The line corresponds to the fit between the relaxation time and the instantaneous conductivity according to $\tau=A / \sigma_{\infty}$ with $A$ denotes a fitting constant. The uncertainty in the determination of the time constants can be significative, i.e., on the same order than the dispersion of the data points. denotes the Boltzmann constant $\left(1.38 \times 10^{-23} \mathrm{~m}^{2} \mathrm{~kg} \mathrm{~s}^{-2} \mathrm{~K}^{-1}\right)$, and $T$ denotes the absolute temperature $(\mathrm{K})$. The product of the ColeCole time constant by the instantaneous conductivity of the mixture is given by

$$
\sigma_{\infty} \tau_{0} \approx \frac{a^{2} e^{2} C_{m}}{k_{b} T}\left(1+3 \varphi_{m}\right)
$$

Because in our experiments, we use the same pyrite, and because the term $\left(1+3 \varphi_{m}\right)$ does not vary in a huge range in our experi-

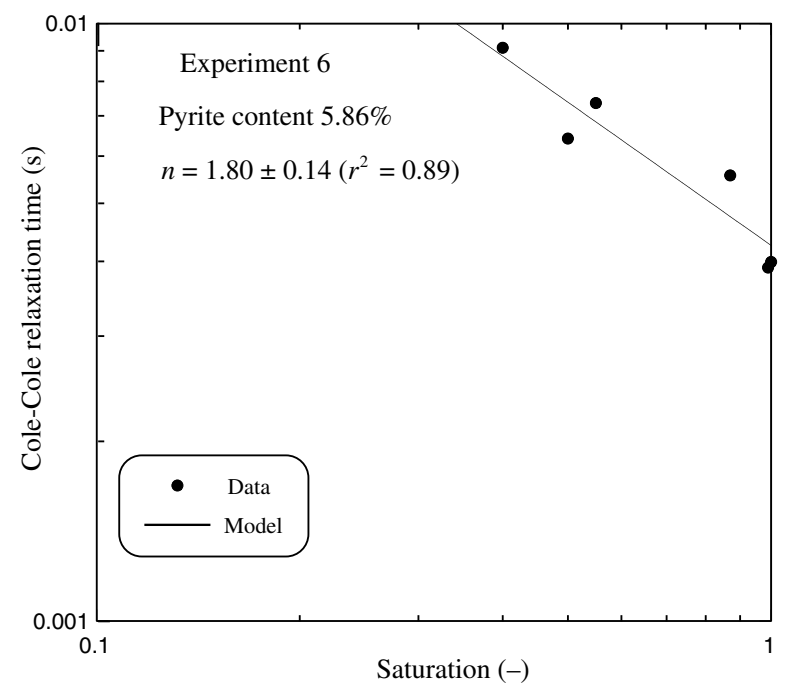

Figure 16. Cole-Cole relaxation time $\tau_{1}$ versus saturation for a representative experiment (experiment 6, volume content of pyrite $5.87 \%$ ). The saturation exponent $n$ obtained by fitting equation 19 is consistent with the value obtained for the background material at high salinity (see Figure 6).

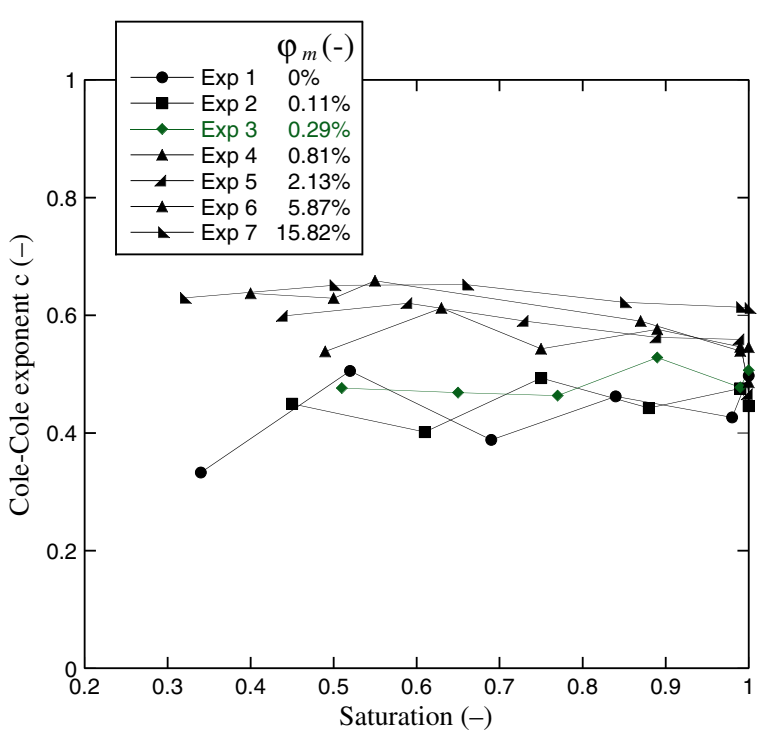

Figure 17. Cole-Cole exponent versus saturation. We see that the two quantities are independent of each other. In other words, the Cole-Cole exponent is distinct for different pyrite content, but its value for a given pyrite content does not change much with saturation. 


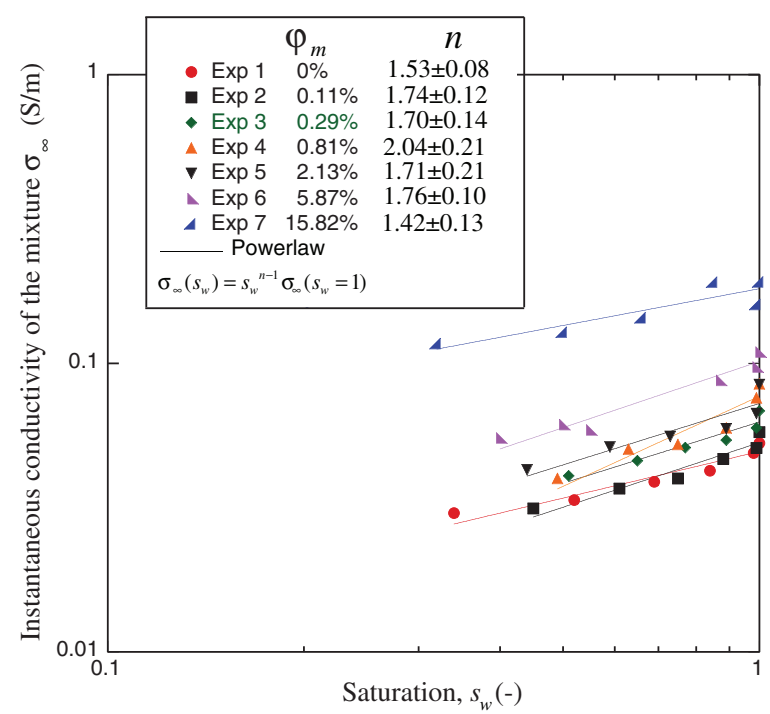

Figure 18. Instantaneous conductivity of the mixture versus saturation for experiments 1-7 during desiccation. The instantaneous conductivity is defined as the conductivity just after the application of the electrical field. It is equivalent to high-frequency conductivity in frequency-domain induced polarization.
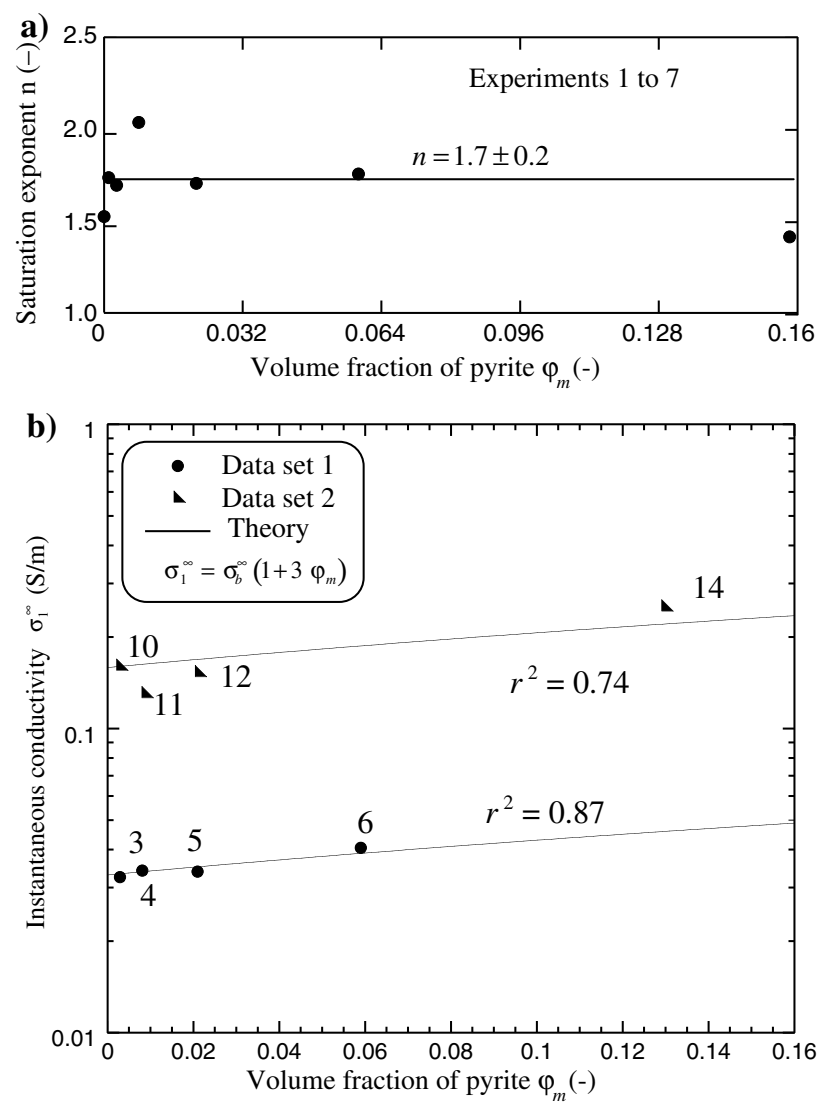

Figure 19. Saturation exponent and instantaneous conductivity versus pyrite content. (a) Saturation exponent versus saturation for experiments 1-7. As expected, the saturation exponent is independent of the volume fraction of pyrite. (b) Instantaneous conductivity versus pyrite content for the low and high salinities. The plain lines correspond to the theory (equation 11). We use here the instantaneous conductivity contribution corresponding to the first polarization contribution discussed in Appendix A. ments, the product $\sigma_{\infty} \tau_{0}$ should be roughly constant or, in other words, the Cole-Cole relaxation time should be inversely proportional to the instantaneous conductivity of the mixture in the presence of pyrite.

Finally, a quantitative relationship can be determined between the quadrature conductivity (measured at the geometric mean of two frequencies $f_{1}$ and $f_{2}$ ) and the normalized chargeability defined as the difference between the in-phase conductivity at frequency $f_{2}>f_{1}$ and the in-phase conductivity at frequency $f_{1}$ (Shuey and Johnson, 1973; Revil et al., 2017c)

Table 3. Characteristics of the material used for the numerical experiment parameters with finite-element simulation.

Parameters

Value

\begin{tabular}{lc}
$D_{(-)}$ & $1.7 \times 10^{-9} \mathrm{~m}^{2} \mathrm{~s}^{-1}$ \\
$D_{(+)}$ & $1.1 \times 10^{-9} \mathrm{~m}^{2} \mathrm{~s}^{-1}$ \\
$D_{(+)}^{m}=D_{(-)}^{m}$ & $2.9 \times 10^{-5} \mathrm{~m}^{2} \mathrm{~s}^{-1}$ \\
$C_{(+)}^{m}=C_{(-)}^{m}$ & $2.8 \times 10^{22} \mathrm{~m}^{-3}$ \\
$\varepsilon_{0}$ & $8.81 \times 10^{-12} \mathrm{~F} \mathrm{~m}^{-1}$ \\
$\varepsilon_{S}$ & $10.9 \varepsilon_{0}$ \\
$\varepsilon_{w}$ & $80 \varepsilon_{0}$ \\
$\phi$ & 0.40 \\
$A$ & $500 \mu \mathrm{m}$ \\
\hline
\end{tabular}

Note: The quantity $C_{( \pm)}^{m}\left(\mathrm{~m}^{-3}\right)$ denotes the charge concentration in the semiconductor grain at equilibrium state, $D_{( \pm)}^{m}\left(\mathrm{~m}^{2} \mathrm{~s}^{-1}\right)$ denotes the diffusion coefficients of the charge carriers in the metallic particle, $D_{( \pm)}$denotes the diffusion coefficients of cations and anions in the solution, and $\varepsilon_{0}, \varepsilon_{S}$, and $\varepsilon_{w}$ denote the permittivity $\left(\mathrm{F} \mathrm{m}^{-1}\right)$ of free space, metallic grain, and electrolyte, respectively (their temperature dependence is small and neglected). The quantity $\phi$ denotes the porosity of the background. The instantaneous conductivity of the metallic grain is $10 \mathrm{~S} \mathrm{~m}^{-1}$ (at $25^{\circ} \mathrm{C}$ ), whereas the conductivity of the solution at $25^{\circ} \mathrm{C}$ is $0.105 \mathrm{~S} \mathrm{~m}^{-1}$. The quantity $a$ denotes half the length of the metallic particle.

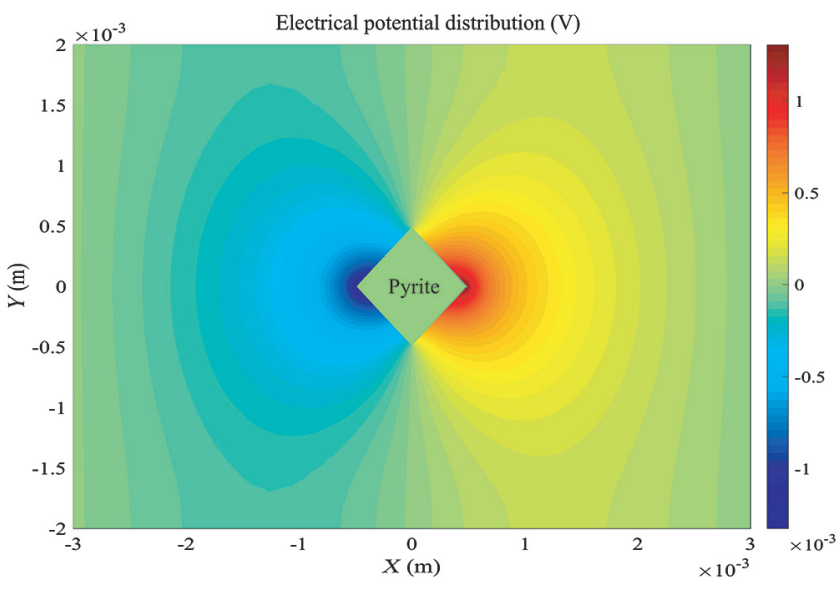

Figure 20. Results of the numerical simulations (with the finiteelement method) showing the dipolar character of the secondary electrical field associated with the polarization of a pyrite grain under the influence of a primary electrical field (see for comparison the sketch shown in Figure $2 b$ ). The simulation is here shown at full water saturation $\left(s_{w}=1\right)$. 


$$
\sigma^{\prime \prime}\left(\sqrt{f_{1} f_{2}}\right) \approx-\frac{M_{n}\left(f_{1}, f_{2}\right)}{\alpha}=-\frac{\sigma^{\prime}\left(f_{2}\right)-\sigma^{\prime}\left(f_{1}\right)}{\alpha} .
$$

The value of $\alpha$ is determined by $\alpha \approx(2 / \pi) \ln A$, where $A$ is the number of decades separating the high and low frequencies (see Revil et al., 2017c). Typically, $\alpha$ is on the order of 8-9 if we consider very low and very high frequencies (e.g., $10 \mathrm{mHz}$ and $10 \mathrm{kHz}$, Revil et al., 2018a) used to define $M_{n}=\sigma_{\infty}-\sigma_{0}$.

Four predictions can be made based on the previous model (equations 1-14). (1) Under the condition of desiccation, the chargeability should be weakly dependent on the saturation. For the samples characterized by a high proportion of semiconductors (typically approximately $0.2 \%$ ), the chargeability should be controlled by the volume fraction of semiconductors as shown in equation 2. (2) The instantaneous conductivity should depend on a predictable way with the saturation accounting for the effect of the saturation on the bulk and surface conductivities. (3) The Cole-Cole relaxation time should be dependent on the saturation through the dependence on saturation of the instantaneous conductivity. In other words, the Cole-Cole relaxation time should be inversely proportional to the
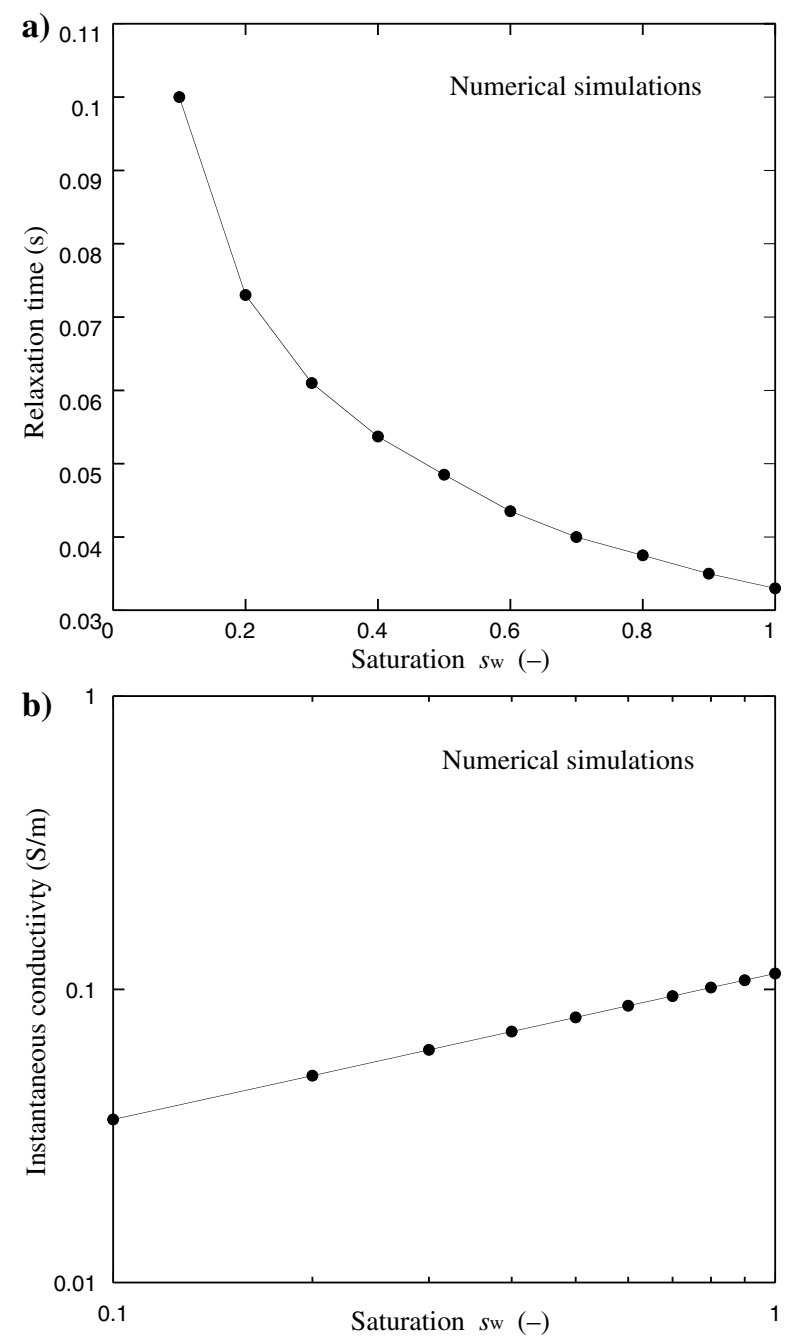

Figure 21. Results of the numerical simulations. (a) Relaxation time versus saturation. (b) Instantaneous conductivity versus saturation showing a power law relationship $\sigma_{1}^{\infty}\left(s_{w}\right)=s_{w}^{n-1} \sigma_{1}^{\infty}\left(s_{w}=1\right)$. instantaneous conductivity when the saturation changes. (4) The Cole-Cole exponent should be independent of the saturation, which implicitly means that all of the time constants should have the same dependence with the saturation.

\section{MATERIALS AND METHODS}

\section{Material}

The background material considered in our experimental study is a natural illite material, which once hydrated appears muddy. We also determined its CEC with the cobalt hexamine chloride method (Ciesielski et al., 1997). We prepared two samples of $2 \mathrm{~g}$ of the clay in a solution of $40 \mathrm{ml}$ of cobalt hexamine. We then centrifuged the samples for $10 \mathrm{~min}$. Then, we did absorbance measurements of the samples with a spectrophotometer and compared them to the absorbance of a standard solution of cobalt hexamine at a $100 \%$ dilution ratio, $75 \%, 50 \%$, and $25 \%$. We found a dilution ratio of $90.22 \%$. We deduced the quantity of cobalt hexamine sorbed at the surface of the clay, and knowing the initial mass of dry clay, we found a CEC of $9.744 \mathrm{meq} / 100 \mathrm{~g}$ or $9401.5 \mathrm{C} \mathrm{kg}^{-1}$ Table 1). The metallic particles used to form the mixture with the background are pyrite grains.

\section{Characterization of the background material}

We first characterized the background material in terms of formation factor $F$ and surface conductivity $\sigma_{s}$. With this in mind, we filled three beakers with demineralized water and $\mathrm{NaCl}$ to get three conductivities of pore water: $0.1,1$, and $10 \mathrm{~S} \mathrm{~m}^{-1}\left(25^{\circ} \mathrm{C}, \mathrm{NaCl}\right)$. In addition, we prepared another beaker with tap water whose conductivity was $0.0589 \mathrm{~S} \mathrm{~m}^{-1}$ at $25^{\circ} \mathrm{C}$. We then added the clay samples to the solution. To reach equilibrium, the mixture was left to rest for one month. The samples were covered during the resting time to avoid evaporation. At the end of the resting period, the conductivity (at $25^{\circ} \mathrm{C}$ ) of the supernatant water for the four samples was 0.0724 , $0.122,0.809$, and $7.396 \mathrm{~S} \mathrm{~m}^{-1}$ for the solutions. Then, we removed

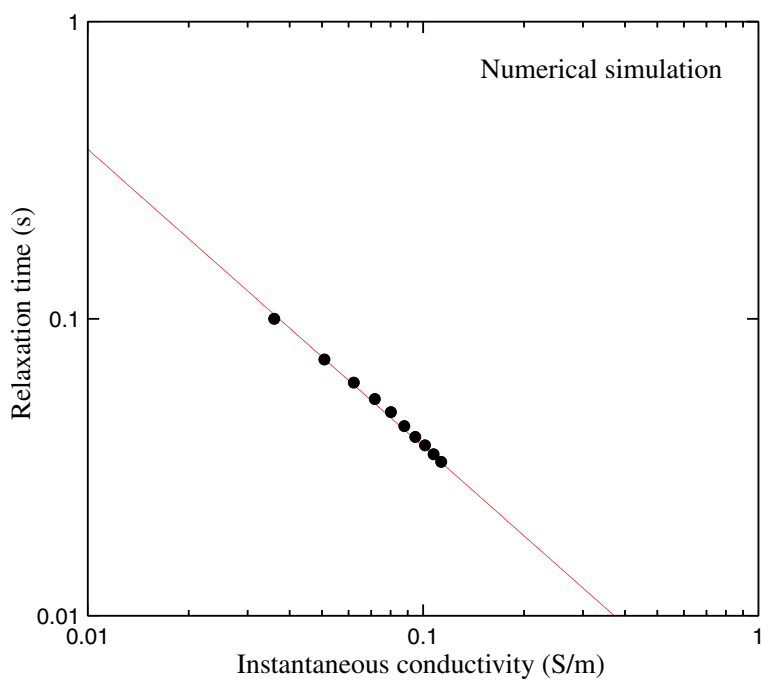

Figure 22. Relaxation time versus instantaneous conductivity of the mixture for the numerical simulation. The numerical simulation shows that the two quantities are inversely proportional to each other, which is consistent with the physical model involving an intraparticle polarization process for the pyrite grain. 
the supernatant water and filled four buckets with the mud. To do the measurements, we used a similar experimental setup as shown by Revil et al. (2017b, 2017c). We performed complex conductivity measurements with a high-precision impedance meter (Zimmermann et al., 2007, 2008) between $10 \mathrm{mHz}$ and $45 \mathrm{kHz}$. The sample holder includes four nonpolarizing $\mathrm{Ag}-\mathrm{AgCl}$ sintered electrodes fixed on a cap (for further discussion, see Revil et al., 2018b). The electrodes are $2 \mathrm{~cm}$ apart, their diameter is $4 \mathrm{~mm}$, and the geometric factor is $16.6 \mathrm{~m}^{-1}$. The data are shown in Figures 3, 4, and 5 and will be analyzed in the next section.

\section{Unsaturated experiments with desiccation}

We performed two sets of experiments at two distinct pore water conductivities and seven pyrite contents. These experiments are labeled experiments 1-14 in Table 2. For both sets of experiments, a homogeneous mixture was prepared with the background clay, demineralized water, and $\mathrm{NaCl}$ to mimic the mixture shown in Figure 1. Once prepared, we closed the core samples and let them rest for approximately 10 days. After this period, the conductivity of the supernatant water was $0.115 \mathrm{~S} \mathrm{~m}^{-1}$ for the first set of experiments (experiments 1-7) and $1.081 \mathrm{~S} \mathrm{~m}^{-1}$ for the second set of experiments (experiments 8-14). Then, we removed the supernatant water and filled seven buckets with the mixture. We added pyrite fragments into those samples to get an approximately log normal

Table 4. Relaxation time for COx sample EST29296.

\begin{tabular}{|c|c|c|c|c|c|c|c|c|}
\hline Saturation & $\tau_{1}(\mathrm{~s})$ & $\tau_{2}(\mathrm{~s})$ & $c_{1}(-)$ & $c_{2}(-)$ & $M_{1}(-)$ & $M_{2}(-)$ & $\sigma_{\infty}(\mathrm{S} / \mathrm{m})$ & $\operatorname{rms}(\%)$ \\
\hline 0.77 & 0.01786 & $1.25 \mathrm{E}-06$ & 0.453 & 0.504 & 0.034 & 0.097 & $3.867 \mathrm{E}-04$ & 0.652 \\
\hline 0.74 & 0.02736 & $6.81 \mathrm{E}-07$ & 0.488 & 0.463 & 0.033 & 0.128 & 3.343E-04 & 0.616 \\
\hline 0.6 & 0.02070 & $2.17 \mathrm{E}-06$ & 0.490 & 0.596 & 0.039 & 0.100 & $2.535 \mathrm{E}-04$ & 0.726 \\
\hline 0.5 & 0.01999 & $4.78 \mathrm{E}-07$ & 0.508 & 0.525 & 0.041 & 0.203 & $1.704 \mathrm{E}-04$ & 0.442 \\
\hline 0.42 & 0.02129 & $5.17 \mathrm{E}-07$ & 0.511 & 0.516 & 0.041 & 0.197 & $1.707 \mathrm{E}-04$ & 0.442 \\
\hline 0.38 & 0.01464 & $1.62 \mathrm{E}-06$ & 0.482 & 0.650 & 0.051 & 0.156 & $1.353 \mathrm{E}-04$ & 0.489 \\
\hline 0.38 & 0.01737 & $1.13 \mathrm{E}-06$ & 0.478 & 0.596 & 0.051 & 0.193 & $1.125 \mathrm{E}-04$ & 0.422 \\
\hline 0.32 & 0.01850 & $5.81 \mathrm{E}-07$ & 0.463 & 0.566 & 0.052 & 0.271 & $9.317 \mathrm{E}-05$ & 0.428 \\
\hline 0.29 & 0.02049 & $9.62 \mathrm{E}-07$ & 0.478 & 0.615 & 0.056 & 0.265 & 7.757E-05 & 0.774 \\
\hline 0.28 & 0.02226 & 8.91E-07 & 0.456 & 0.579 & 0.058 & 0.295 & $6.546 \mathrm{E}-05$ & 0.498 \\
\hline 0.27 & 0.02016 & $9.62 \mathrm{E}-07$ & 0.466 & 0.593 & 0.056 & 0.311 & 6.144E-05 & 0.461 \\
\hline 0.26 & 0.02058 & $1.17 \mathrm{E}-06$ & 0.457 & 0.599 & 0.059 & 0.305 & $5.411 \mathrm{E}-05$ & 0.570 \\
\hline 0.24 & 0.02549 & $1.38 \mathrm{E}-06$ & 0.471 & 0.588 & 0.061 & 0.335 & $3.822 \mathrm{E}-05$ & 0.577 \\
\hline 0.22 & 0.02533 & $9.68 \mathrm{E}-07$ & 0.447 & 0.596 & 0.060 & 0.401 & $3.622 \mathrm{E}-05$ & 0.517 \\
\hline 0.21 & 0.02367 & $1.20 \mathrm{E}-06$ & 0.428 & 0.623 & 0.068 & 0.410 & $3.067 \mathrm{E}-05$ & 0.666 \\
\hline 0.2 & 0.03648 & $1.34 \mathrm{E}-06$ & 0.447 & 0.611 & 0.063 & 0.455 & $2.440 \mathrm{E}-05$ & 0.659 \\
\hline 0.2 & 0.02587 & $1.46 \mathrm{E}-06$ & 0.419 & 0.634 & 0.068 & 0.457 & $2.470 \mathrm{E}-05$ & 0.511 \\
\hline 0.196 & 0.03883 & 8.27E-07 & 0.442 & 0.586 & 0.054 & 0.554 & $2.368 \mathrm{E}-05$ & 0.510 \\
\hline 0.19 & 0.03878 & $1.03 \mathrm{E}-06$ & 0.420 & 0.604 & 0.060 & 0.566 & $1.876 \mathrm{E}-05$ & 0.527 \\
\hline 0.18 & 0.04390 & 1.79E-06 & 0.385 & 0.643 & 0.060 & 0.631 & $1.244 \mathrm{E}-05$ & 0.739 \\
\hline 0.14 & 0.02679 & $1.63 \mathrm{E}-06$ & 0.298 & 0.666 & 0.059 & 0.769 & $7.020 \mathrm{E}-06$ & 0.986 \\
\hline 0.06 & 0.00115 & $2.06 \mathrm{E}-06$ & 0.181 & 0.722 & 0.032 & 0.932 & $1.100 \mathrm{E}-06$ & 2.081 \\
\hline
\end{tabular}

Note: Cole-Cole parameters using the double Cole-Cole model described in Appendix A. distribution of the volume content of the metallic particles. We form seven samples with a volume fraction of pyrite of $0 \%, 0.11 \%$, $0.29 \%, 0.81 \%, 2.13 \%, 5.87 \%$, and $15.82 \%$ for the first set of experiments and seven additional samples with a volume fraction of pyrite of $0 \%, 0.11 \%, 0.30 \%, 0.89 \%, 2.13 \%, 5.79 \%$, and $13.00 \%$ for the second set of experiments.

For these 14 experiments, spectral-induced polarization measurements were performed from $100 \mathrm{mHz}$ to $45 \mathrm{kHz}$ with an imposed injection voltage of $0.5 \mathrm{~V}$ for experiments $1-7$ and $1 \mathrm{~V}$ for experiments 8-14. The data are shown in Figures 6, 7, 8, 9, and 10. Measurements were done every day on each sample during their desiccation. Between the measurements, the buckets containing the mixture were not covered to get a gradual desaturation of samples at the relative humidity of the room (approximately 40\%) and at the room temperature of approximately $22^{\circ} \mathrm{C}$. We also weighed the samples every day to determine the evolution of the saturation. Because the weight loss of the sample is due to a water loss, we can monitor the water volume and deduce the saturation using the following equation:

$$
s_{w}=\frac{V_{w} \rho_{\text {mix }}}{\phi W_{\text {mix }}},
$$

where $V_{w}$ is the volume of water and $\rho_{\text {mix }}$ and $W_{\text {mix }}$ are the density and the mass of the mixture without pyrite, respectively. The density of the mixture is given by $\rho_{\text {mix }}=\phi \rho_{w}+(1-\phi) \rho_{g}$, where the density of the pore water is $1000 \mathrm{~kg} \mathrm{~m}^{-3}$ and the grain density $\rho_{g}$ is $2650 \mathrm{~kg} \mathrm{~m}^{-3}$. The porosity that we consider in this paper is the porosity of the background material, not the porosity of the mixture (pyrite plus background). The initial volume of water was determined by

$$
V_{w}^{0}=\frac{\phi W_{\mathrm{mix}}^{0}}{\rho_{\mathrm{mix}}},
$$

with $W_{\text {mix }}^{0}$ being the initial mass of the mixture without pyrite. The inversion of the Cole-Cole parameters is done with the approach described in Appendix A and discussed in detail by Qi et al. (2018). Two spectra are shown in Figure 7a (experiment 4 , low pyrite content) and $7 \mathrm{~b}$ (experiment 14 , high pyrite content). Figure 8 shows the grain size distribution of the pyrite grains used in the mixtures. It can be represented fairly well by a log normal distribution.

\section{RESULTS}

\section{Characterization of the background}

Figure 4a shows the in-phase conductivity of the background for four salinities. These data are used to determine the formation factor and surface conductivity of the background (reported in Table 1). Figure $4 \mathrm{~b}$ illustrates the quadrature conductivity of the background for four salinities. We observed a quite strong dependence of the quadrature conductivity with the pore water conductivity. This dependence is explained well with the simple model described in Appendix B. 
Figure 5 shows that for the illite sample used in the present study, the surface conductivity and quadrature conductivity are consistent with the data reported by Revil et al. (2017c) for smectite-rich soils. Figure 6 shows the conductivity data at two salinities versus saturation. These data, performed in condition of desiccation, are used to estimate the value of the second Archie exponent $n$, which is found to be between 1.42 and 1.79 . The difference between the two values is possibly due to different packing conditions in the two experiments. The saturation exponents are consistent between the in-phase and quadrature conductivities.

\section{Cole-Cole parameters for the mixtures}

Figures 9 and 10 show four examples of data fitting by the double Cole-Cole model introduced in Appendix A (equation A-1). This fitting model should not be mistaken with the physical model described above in equations 1-13. All seven Cole-Cole parameters used in the fitting Cole-Cole model are used as model parameters and inverted using the procedure described in more detail by Qi et al. (2018). The real and imaginary parts of the complex conductivity are well reproduced by this model. Because the investigated frequency band is limited to $45 \mathrm{kHz}$, we discuss only the low-frequency polarization in the following, i.e., the parameters $M_{1}, c_{1}, \tau_{1}$, and $\sigma_{1}^{\infty}$.

The chargeability $M$ is shown as a function of saturation and pyrite content in Figures 11, 12, 13 , and 14 for experiments 1-14. In first approximation, there is a fair agreement between the predictions of our model (equations 1-13) and the experimental data. In Figure 11a, we plot the chargeability $M$ as a function of the saturation for the lowest salinity. In Figure 11a and 11b, the chargeability is defined in equation 1 with the DC conductivity determined from the in-phase conductivity at $0.1 \mathrm{~Hz}$ and the high-frequency conductivity determined by the in-phase conductivity at $45 \mathrm{kHz}$. Our physical model is described in equations 2 and 9 for desiccation leading to the following explicit relationship:

$$
M_{1}=\frac{9}{2} \varphi_{m}+\frac{\rho_{g} \lambda \mathrm{CEC}}{\phi \sigma_{w}^{s}+\rho_{g} B \mathrm{CEC}} .
$$

For the lowest salinity, the last term of equation 17 (corresponding to the background chargeability) is dominated by the surface conductivity and is close to $R=0.10$. Equation 17 shows that the chargeability should depend only on the volume content of pyrite $\varphi_{m}$ and not on the saturation $s_{w}$. The agreement between the chargeability data and the model (plain lines) is rather good. However, for the lowest pyrite contents, we observe that the chargeability increases when the saturation decreases. The most plausible explanation is that the increase of the salinity in the pore water increases the value of the background chargeability (Zhang et al., 2019). Indeed, Niu et al. (2016, their Figure 11) show that the ratio between the quadrature conductivity and the surface conductivity increases slightly with the salinity. Because (1) the quadrature conductivity and the normal- ized chargeability are proportional to each other (see equation 14), (2) the background chargeability is essentially the background normalized chargeability to the surface conductivity at low salinity, (3) the ratio of the quadrature conductivity to surface conductivity increases with the salinity, and (4) salinity increases during the decrease of the saturation in desiccation, it follows that the background chargeability is expected to increase during the decrease of the saturation. This effect should disappear at higher salinities. An alternative way to plot the data is to plot the chargeability as a function of the pyrite content (Figure 11b). A comparison with equation 2 indicates a fair comparison between the physical model and the chargeability obtained from the fitting model applied to the data. In Figure 12, we plot only the component $M_{1}$ determined from the fitting model as described in Appendix A. This component reflects only the pyrite content at low values of the pyrite contents; therefore, $M_{2}$ corresponds to the clay contribution for these low pyrite contents. At higher pyrite contents (above $0.5 \%$ ), contribution 1 is the sum of the pyrite and clay contributions.

The same exercise is now repeated for the highest salinity. In this case, equation 17 still applies but the background chargeability is expected to be lower by comparison with its value at low salinity. This is clearly shown in Figures 13 and 14 with a background chargeability $M_{b}=2.9 \times 10^{-2}$. The saturation effect on the chargeability
Table 5. Relaxation time for COx sample EST29300.

\begin{tabular}{lcccccccc} 
Saturation & $\tau_{1}(\mathrm{~s})$ & $\tau_{2}(\mathrm{~s})$ & $c_{1}(-)$ & $c_{2}(-)$ & $M_{1}(-)$ & $M_{2}(-)$ & $\sigma_{\infty}(\mathrm{S} / \mathrm{m})$ & $\mathrm{rms}(\%)$ \\
\hline 0.75 & 0.01987 & $7.52 \mathrm{E}-07$ & 0.422 & 0.454 & 0.062 & 0.134 & $2.029 \mathrm{E}-04$ & 0.421 \\
0.74 & 0.01824 & $1.97 \mathrm{E}-06$ & 0.421 & 0.525 & 0.067 & 0.102 & $1.855 \mathrm{E}-04$ & 0.537 \\
0.69 & 0.01971 & $1.78 \mathrm{E}-06$ & 0.439 & 0.538 & 0.068 & 0.117 & $1.666 \mathrm{E}-04$ & 0.722 \\
0.55 & 0.02736 & $2.02 \mathrm{E}-06$ & 0.463 & 0.546 & 0.067 & 0.132 & $1.260 \mathrm{E}-04$ & 0.700 \\
0.52 & 0.02591 & $1.30 \mathrm{E}-06$ & 0.445 & 0.529 & 0.069 & 0.151 & $1.230 \mathrm{E}-04$ & 0.446 \\
0.47 & 0.02407 & $1.79 \mathrm{E}-06$ & 0.443 & 0.577 & 0.077 & 0.141 & $1.059 \mathrm{E}-04$ & 0.492 \\
0.41 & 0.03433 & $8.01 \mathrm{E}-07$ & 0.454 & 0.489 & 0.075 & 0.205 & $8.215 \mathrm{E}-05$ & 0.505 \\
0.37 & 0.03275 & $1.33 \mathrm{E}-06$ & 0.449 & 0.552 & 0.085 & 0.195 & $6.644 \mathrm{E}-05$ & 0.529 \\
0.34 & 0.03389 & $1.38 \mathrm{E}-06$ & 0.444 & 0.565 & 0.085 & 0.210 & $6.200 \mathrm{E}-05$ & 0.563 \\
0.31 & 0.04518 & $3.47 \mathrm{E}-07$ & 0.444 & 0.467 & 0.074 & 0.309 & $6.002 \mathrm{E}-05$ & 0.496 \\
0.3 & 0.03623 & $7.60 \mathrm{E}-07$ & 0.404 & 0.531 & 0.093 & 0.272 & $4.691 \mathrm{E}-05$ & 0.313 \\
0.27 & 0.04317 & $9.78 \mathrm{E}-07$ & 0.438 & 0.533 & 0.087 & 0.287 & $3.825 \mathrm{E}-05$ & 0.695 \\
0.26 & 0.03914 & $1.35 \mathrm{E}-06$ & 0.419 & 0.576 & 0.093 & 0.287 & $3.313 \mathrm{E}-05$ & 0.649 \\
0.25 & 0.04785 & $1.08 \mathrm{E}-06$ & 0.419 & 0.543 & 0.090 & 0.326 & $2.985 \mathrm{E}-05$ & 0.600 \\
0.24 & 0.04748 & $1.30 \mathrm{E}-06$ & 0.419 & 0.563 & 0.094 & 0.327 & $2.710 \mathrm{E}-05$ & 0.702 \\
0.21 & 0.06670 & $1.10 \mathrm{E}-06$ & 0.419 & 0.541 & 0.094 & 0.393 & $1.993 \mathrm{E}-05$ & 0.676 \\
0.2 & 0.06482 & $9.19 \mathrm{E}-07$ & 0.400 & 0.549 & 0.094 & 0.424 & $1.849 \mathrm{E}-05$ & 0.601 \\
0.19 & 0.06768 & $1.29 \mathrm{E}-06$ & 0.397 & 0.589 & 0.097 & 0.439 & $1.473 \mathrm{E}-05$ & 0.663 \\
0.188 & 0.07301 & $9.73 \mathrm{E}-07$ & 0.388 & 0.574 & 0.093 & 0.489 & $1.432 \mathrm{E}-05$ & 0.595 \\
0.183 & 0.07715 & $1.08 \mathrm{E}-06$ & 0.385 & 0.563 & 0.094 & 0.481 & $1.383 \mathrm{E}-05$ & 0.609 \\
0.175 & 0.08855 & $1.13 \mathrm{E}-06$ & 0.392 & 0.574 & 0.094 & 0.516 & $1.172 \mathrm{E}-05$ & 0.604 \\
0.17 & 0.11743 & $3.92 \mathrm{E}-07$ & 0.395 & 0.525 & 0.070 & 0.646 & $1.278 \mathrm{E}-05$ & 0.466 \\
0.16 & 0.13477 & $8.33 \mathrm{E}-07$ & 0.381 & 0.565 & 0.079 & 0.641 & $9.230 \mathrm{E}-06$ & 0.564 \\
0.11 & 0.19443 & $9.27 \mathrm{E}-07$ & 0.319 & 0.598 & 0.061 & 0.807 & $3.550 \mathrm{E}-06$ & 0.841
\end{tabular}

Note: Cole-Cole parameters using the double Cole-Cole model described in Appendix A. 
has been reduced. For this data set too, there is a fair agreement between the model predictions (the plain lines) and the data determined from the fitting model.

In Figure 15, we show the Cole-Cole relaxation time $\tau_{1}$ as a function of the instantaneous conductivity of the mixture $\sigma_{1}^{\infty}$. The physical model (equation 13) implies that

$$
\tau_{1} \approx \frac{a^{2} e^{2} C_{m}}{k_{b} T \sigma_{1}^{\infty}}\left(1+3 \varphi_{m}\right)
$$

Therefore, the physical model implies that the Cole-Cole relaxation time $\tau_{1}$ should be inversely proportional to the instantaneous conductivity of the mixture $\sigma_{1}^{\infty}$ at a given volume fraction of pyrite. This is in agreement with the data shown in Figure 15. The scatter shown in Figure 15 is due to the fact that the experiments are conducted at different volume fractions of pyrite. We can now plot the relaxation time as a function of the saturation for a given volume content of pyrite. In this case, the conductivity of the mixture varies with the saturation according to a power law relationship, i.e., $\sigma_{1}^{\infty}\left(s_{w}\right)=s_{w}^{n-1} \sigma_{1}^{\infty}\left(s_{w}=1\right)$, where $\sigma_{1}^{\infty}\left(s_{w}=1\right)$ denotes the value of the instantaneous conductivity of the mixture at full water saturation. Combined with equation 18 , this yields
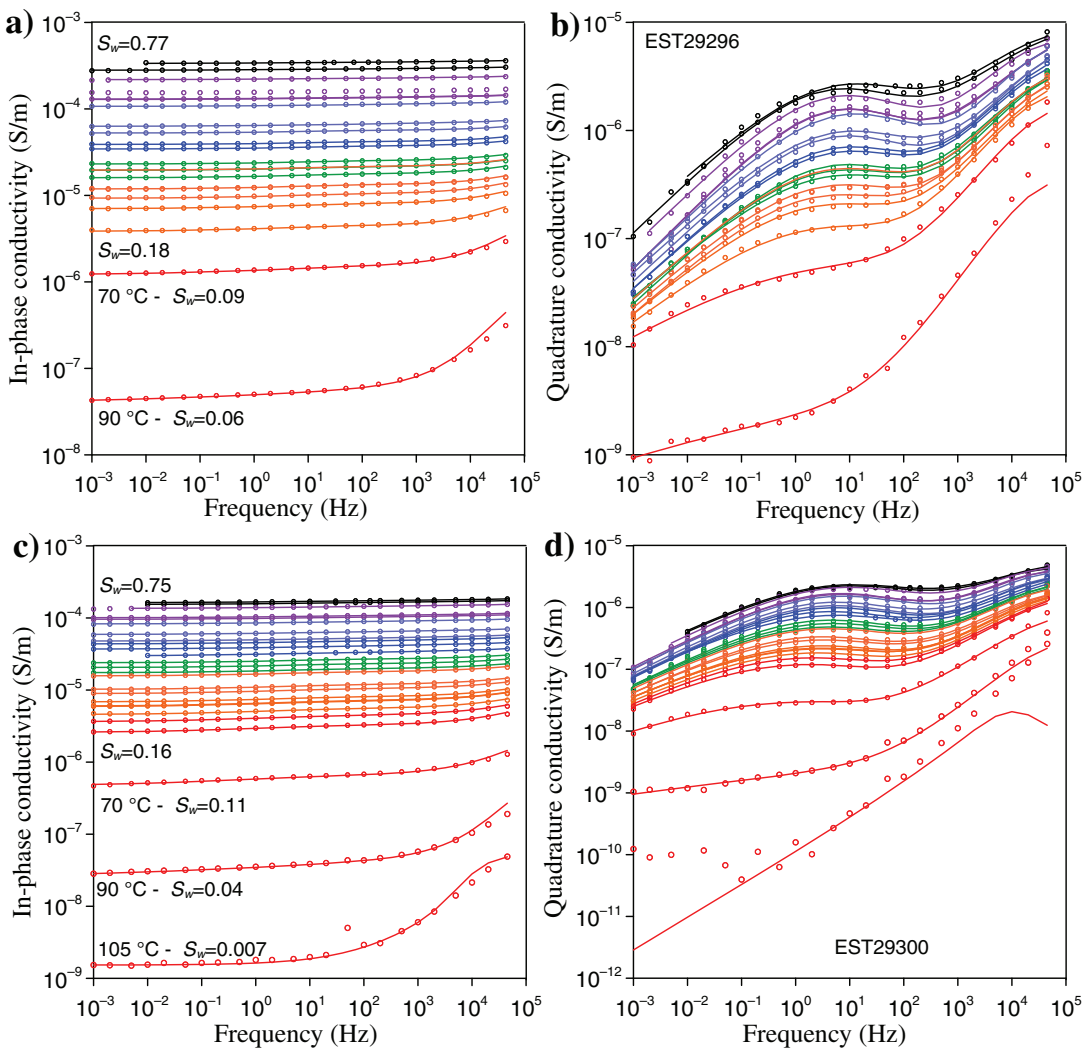

Figure 23. Complex conductivity data for samples EST29296 and EST29300 (COx clayrock samples from the Paris Basin) undergoing desiccation. The data (the symbols) are fitted by a double Cole-Cole model in complex conductivity (the plain lines). For each saturation (in the range of 0.77-0.06), we have determined the Cole-Cole parameters. ( $a$ and b) Sample EST29296. (c and d) Sample EST29300. The bad fit corresponds to the data with the lowest phase values.

$$
\tau_{1}\left(s_{w}\right) \approx s_{w}^{1-n} \frac{a^{2} e^{2} C_{m}}{k_{b} T \sigma_{1}^{\infty}\left(s_{w}=1\right)}\left(1+3 \varphi_{m}\right) .
$$

According to equation 19, the relaxation time $\tau_{1}$ depends to the saturation according to a power law function. Taking $n=2$, the relaxation time $\tau_{1}$ should be inversely proportional to the saturation. In Figure 16, we show for one experiment (at a fixed volume content of pyrite) that indeed the relaxation time is inversely proportional to the saturation (the plain line).

The Cole-Cole exponent $c_{1}$ is shown as a function of the saturation in Figure 17 for different values of the pyrite content. Here again in agreement with the theory, the Cole-Cole exponent appears to be essentially independent of the saturation. This implies in turn that all of the relaxation times should depend the same way on the saturation because the broadness of the distribution (measured by $c_{1}$ ) seems preserved.

In Figure 18, we plot the instantaneous conductivity $\sigma_{1}^{\infty}$ versus he saturation $s_{w}$. As predicted by the model (see equations 7 and , the data can be fitted by a power law relationship with respect to the saturation, i.e., $\sigma_{1}^{\infty}\left(s_{w}\right)=s_{w}^{n-1} \sigma_{1}^{\infty}\left(s_{w}=1\right)$. The fit provides the value of the instantaneous conductivity at full saturation $\sigma_{1}^{\infty}\left(s_{w}=1\right)$ and the saturation exponent $n$. These two quantities are shown as a function of the saturation in Figure 19. As expected, the exponent $n$ is independent of the pyrite content, and it is equal to $1.7 \pm 0.2$ (Figure 19a). The instantaneous conductivity of the mixture at saturation $\sigma_{1}^{\infty}\left(s_{w}=1\right)$ linearly increases with the pyrite content $\varphi_{m}$ as predicted in equation 11 .

\section{NUMERICAL MODELING}

\section{Description of the approach}

To study the induced polarization around a metallic grain, Abdulsamad et al. (2017) solve the Poisson-Nernst-Planck equation in 2D with the finite-element approach using the values of the parameters reported in Table 3. The approach was simplified by Revil et al. (2018a), who demonstrate that the dominant mechanism for large grains (e.g., $>500 \mu \mathrm{m}$ ) is the polarization of the metallic grain itself so we could consider the polarizable metallic grain in a purely ohmic background neglecting the formation of field-induced diffuse layers in the vicinity of the metallic particles. Therefore, following this approach, we consider a metallic particle with an ohmic background material undergoing desiccation. Because the equations are the same as in Revil et al. (2018a), they will not be repeated here. The shape of the metallic particle is a square to mimic the classic cubic shape of pyrite in nature. The instantaneous and DC conductivities of the background material are given from equations 4 and 5 by

$$
\begin{gathered}
\sigma_{b}^{\infty}\left(s_{w}\right)=s_{w}^{n-1} \sigma_{b}^{\infty}\left(s_{w}=1\right), \\
\sigma_{b}^{0}\left(s_{w}\right)=s_{w}^{n-1} \sigma_{b}^{0}\left(s_{w}=1\right) .
\end{gathered}
$$


The simulations are performed for a range of pore water saturations $s_{w}$ in the range of 1 (full saturation) to 0.1 with a linear saturation step of 0.1 and $n=1.5$.

\section{Results}

Figure 20 shows an example of the numerical simulation of the polarization phenomena in the presence of pyrite grain. We see clearly in this figure that the secondary voltage implies that the grain has acquired a dipole moment. If we would pick up the voltages at two electrodes $M$ and $N$ on a smaller volume, the voltage difference would be higher and the chargeability would be higher for the higher pyrite fraction in the volume considered for the calculation. These simulations are used to create a synthetic data set that can be compared with the real data discussed above. The numerical result (the decay curve or discharge curve) can be fitted with a Cole-Cole
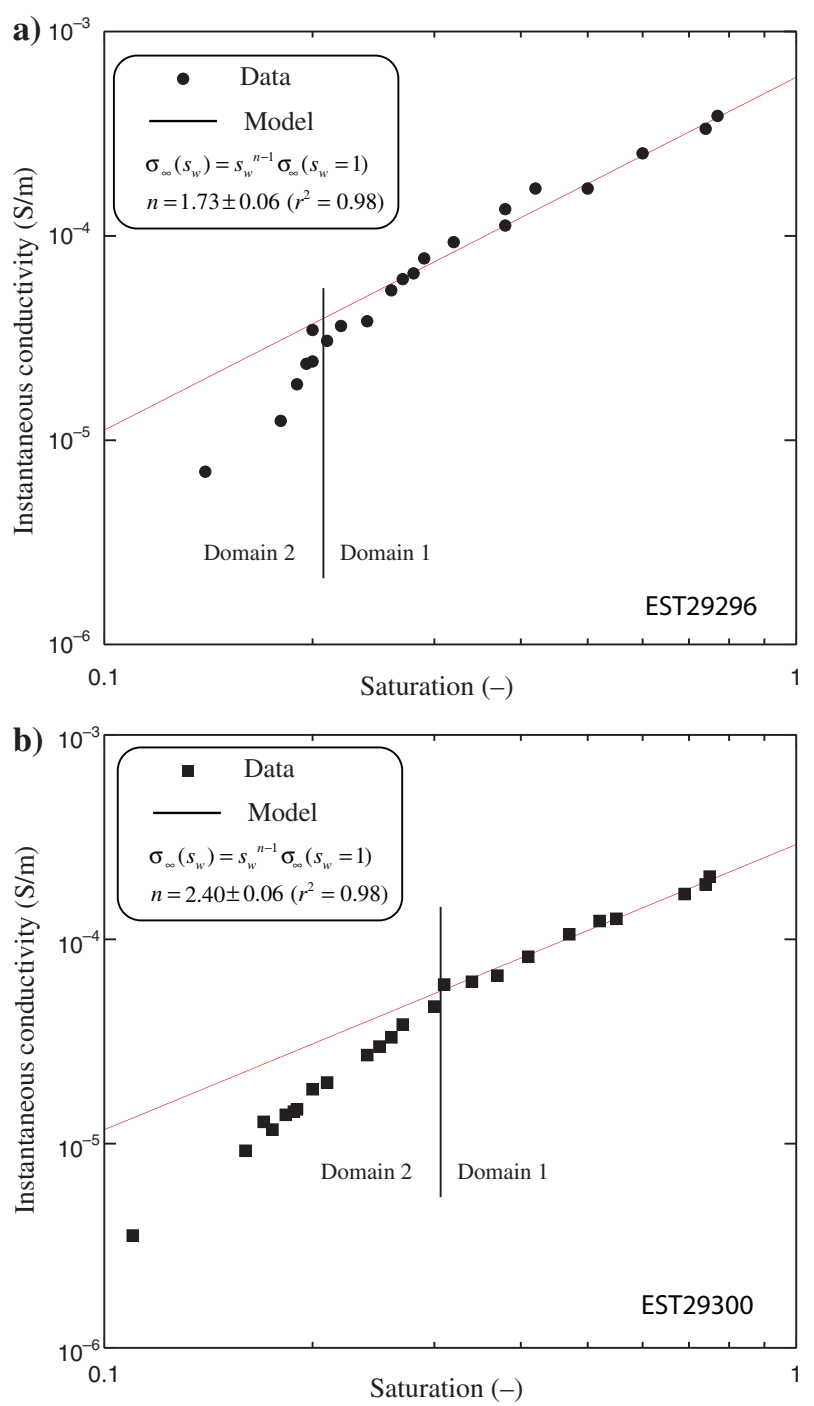

Figure 24. Instantaneous conductivity versus saturation for the COx clayrock undergoing desiccation. In domain 1, the instantaneous conductivity data follow a power law function of saturation, whereas there is a clear departure of this trend in domain 2. Domain 2 may correspond to the hydration water. (a) Sample EST29296 and (b) sample EST29300. model, which actually takes the form of a Debye model for a single grain ( $c=1$, no leaking effect).

The Cole-Cole relaxation time and the instantaneous conductivity of the mixture are shown in Figure 21. We clearly observe that the magnitude of the Cole-Cole relaxation time increases when the saturation decreases (Figure 21a). The trend is actually consistent with $\tau_{1}\left(s_{w}\right) \sim 1 / \sqrt{s_{w}}$ in agreement with equation 19 and $n=1.5$. The instantaneous conductivity of the mixture decreases with decreasing the saturation as shown in Figure 21b. The trend is consistent with $\sigma_{1}^{\infty}\left(s_{w}\right) \sim \sqrt{s_{w}}$. In Figure 22, we observe that

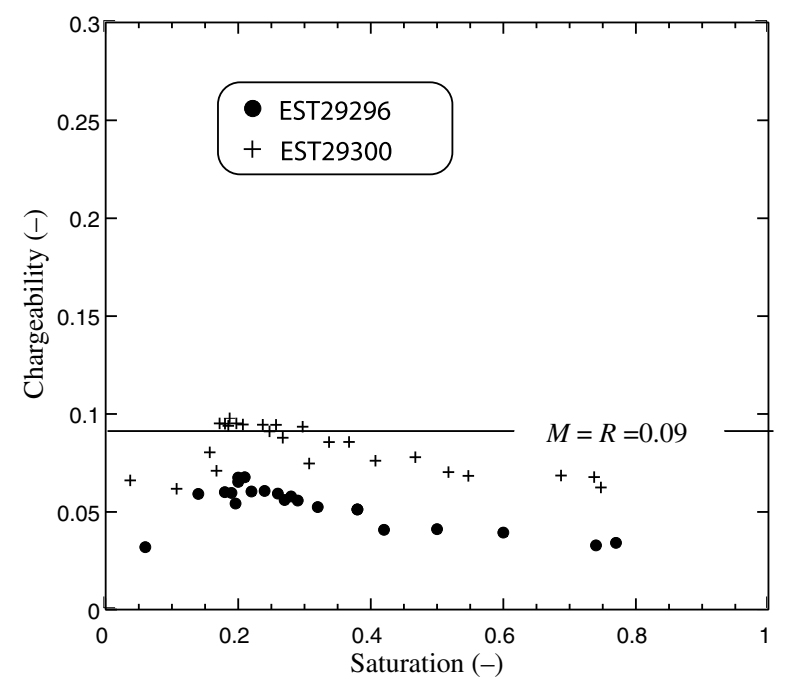

Figure 25. Chargeability versus saturation for the COx clayrock undergoing desiccation. Samples EST29296 and EST29300. The increase of the chargeability with the decrease of the saturation may be due to the increase of the salinity during desiccation.

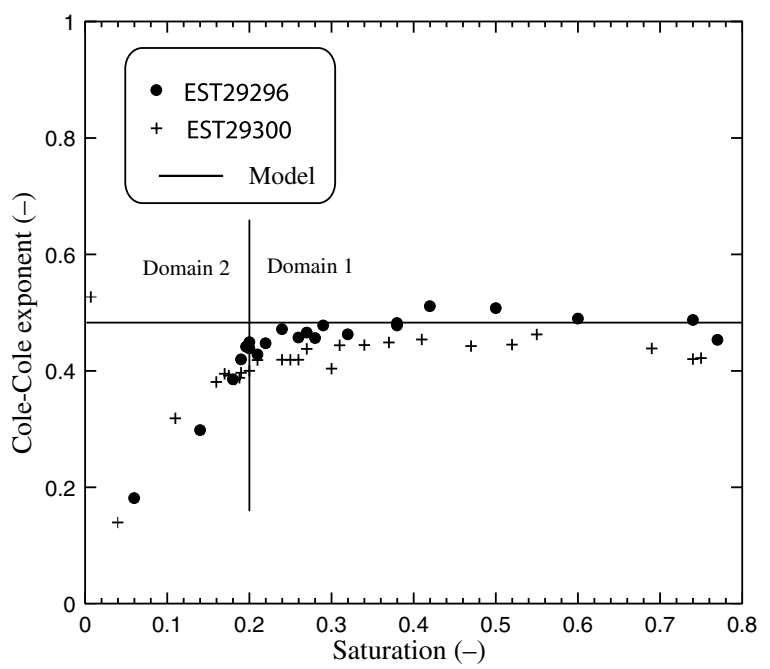

Figure 26. Cole-Cole exponent versus saturation for the COx clayrock undergoing desiccation. The data show a constant Cole-Cole exponent $c_{1}$ in domain 1 with a mean value of 0.44 . There is a departure from this trend in domain 2 in which the Cole-Cole exponent gradually falls down indicating flatter spectra. We do not provide a correlation coefficient here because this is not a fit but a comparison between the model and the data. 
the relaxation time is inversely proportional to the instantaneous conductivity of the mixture in agreement with the physical model, see equation 18, and the experimental data shown in Figure 15.

\section{APPLICATION TO THE COx CLAYROCK}

We can now compare our results to the complex conductivity data obtained with the COx clayrock by Jougnot et al. (2010). The COx clayrock contains a minor amount of pyrite, and we are interested to see how this pyrite may affect the complex conductivity spectra during desiccation. In Figure 23, we show the complex conductivity spectra for two core samples (samples EST29296 and EST29300) at different water saturations during desiccation. The plain lines in Figure 23 correspond to the fit of the data with the double Cole-Cole model discussed in Appendix A. The Cole-Cole parameters are reported in Tables 4 and 5. First, we note that this complex conductivity model fits the data very well nearly at all the saturations. The
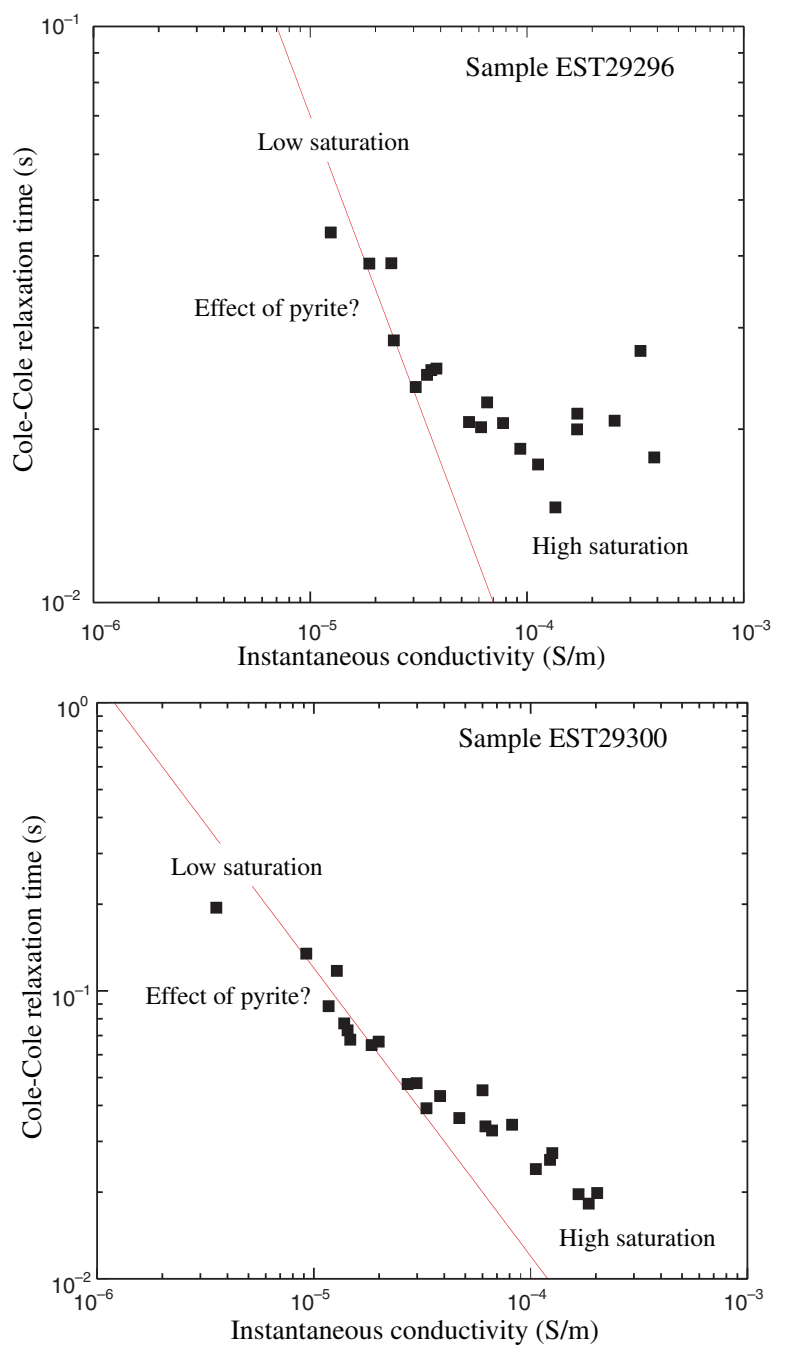

Figure 27. Cole-Cole relaxation time versus the instantaneous conductivity of the mixture for the COx clayrock undergoing desiccation. (a) Sample EST29296. (b) Sample EST29300. The plain lines correspond to the inverse relationship between the Cole-Cole relaxation time and the instantaneous conductivity predicted for pyritedominated responses.
Cole-Cole parameters discussed below are those associated with the low-frequency part of the spectra.

The two COx samples, EST29296 and EST29300, are 0.108 and $0.167 \mathrm{~m}$ long cylinders with radii of 0.063 and $0.055 \mathrm{~m}$, respectively. They were not processed after sampling. That is, they contain the in situ pore water solution and were not resaturated with a synthetic pore water. Their initial saturation state was not fully saturated $\left(s_{w}<0.80\right)$, and the saturation was estimated afterward as described by Jougnot et al. (2010). The data presented in Figure 23 were obtained by repeating spectral induced polarization (SIP) measurements with the exact same setup (electrode location and measurement settings) at different water saturations following the procedure proposed by Cosenza et al. (2007): First, there is a natural drying period of 29 days, followed by heating steps in an oven $\left(24 \mathrm{~h}\right.$ at $70^{\circ} \mathrm{C}, 90^{\circ} \mathrm{C}$, and $\left.105^{\circ} \mathrm{C}\right)$.

In Figure 24, we plot the instantaneous conductivity of the rock sample as a function of the saturation. According to equations 7 and 11 , for the desiccation we have $\sigma_{\infty}=s_{w}^{n-1} \sigma_{\infty}\left(s_{w}=1\right)$. This power law relationship is used to fit the data and provide the value of the instantaneous conductivity of the rock at saturation $\sigma_{\infty}\left(s_{w}=1\right)$ and the saturation exponent $n$ (1.73 for EST29296 and 2.40 for EST29300) for the high water content of domain 1. Equation 20 fits the data very well down to a critical value of saturation between $20 \%$ and $30 \%$. Below this critical saturation, the residual pore water is possibly bound (hydration) water and the conductivity saturation trend does not follow an Archie-type behavior anymore, and the new trend is not captured by our model in domain 2 .

In Figure 25, we plot the chargeability versus the pore water saturation. According to our model and during desiccation, the chargeability should be independent of the saturation. We see a small increase of the chargeability (by a factor of two) when the saturation decreases. Below a critical saturation of approximately $20 \%$, the chargeability associated with the polarization of the electrical double layer of the grains seems to decrease. Similarly, Figure 26 shows the Cole-Cole exponent versus the pore water saturation. The ColeCole exponent of the two core samples is independent of the saturation down to $20 \%$ (with a mean value of approximately 0.45 ), and it falls down with the decrease of the saturation below this value. The behavior is consistent with the spectra becoming very flat at very low water contents (see Figure 23).

Finally, in Figure 27, we show the Cole-Cole relaxation time (for the low-frequency polarization) as a function of the instantaneous conductivity of the rock. At low saturations only, the Cole-Cole relaxation time is inversely proportional to the instantaneous conductivity of the rock, which could indicate an effect of pyrite (see Figures 15 and 22). Indeed, in the presence of pyrite, the Cole-Cole relaxation time is inversely proportional to the saturation according to equation 19. At higher water contents, the polarization of the background is dominating the overall observed polarization response and the Cole-Cole relaxation time is not expected to depend on the conductivity of the material anymore. A complete complex conductivity model able to include the two contributions together is still missing and will be the focus of a future work.

\section{CONCLUSION}

We have performed 14 experiments at different pore water saturations and pyrite content. The background material is a natural illitic clay, in which electrical properties have been characterized. The model we developed is an extension of our prior models in which the polarization of the nonmetallic grains is due to the Stern 
layer coating these grains, whereas the polarization of the metallic grains is an intragrain polarization mechanism. Indeed, the migration of the charge carriers inside the metallic particles is submitted to electrochemical potential gradients; therefore, because of its finite dimensions, the particle is expected to polarize in an electrical field. The extension was done to include explicitly the effect of saturation and the effect of desiccation when the salt remains segregated into the liquid water phase. The spectra were fitted with a Cole-Cole model. Based on our model, four predictions were made, which could be tested to the experimental data. (1) The chargeability is observed to be weakly dependent on saturation for desiccation. When the background chargeability is sufficiently small, the chargeability is independent of salinity. (2) The instantaneous conductivity should depend on a predictable way with the saturation accounting for the effect of the saturation on the bulk and surface conductivities. (3) The ColeCole relaxation time should be dependent on the saturation through the dependence on saturation of the instantaneous conductivity. In other words, the Cole-Cole relaxation time should be inversely proportional to the instantaneous conductivity when saturation changes. (4) The Cole-Cole exponent is independent of the saturation.

\section{ACKNOWLEDGMENTS}

We thank E. Zimmermann for his impedance meter and his work in the development of the metrology of induced polarization. We thank the French National Radioactive Waste Management Agency (ANDRA) for its support. The Ph.D. thesis of T. Tartrat is supported by ANDRA. We thank the editor C. Farquharson, A. Weller, and two anonymous referees for their very constructive comments.

\section{DATA AND MATERIALS AVAILABILITY}

Data associated with this research are available and can be obtained by contacting the corresponding author.

\section{APPENDIX A}

\section{DOUBLE COLE-COLE PARAMETERIZATION AND INVERSION}

To account for the polarization of the background (made by illite) and the polarization associated with the pyrite, we use a double Cole-Cole model written as

$$
\sigma *=\sigma_{\infty}\left(1-\frac{M_{1}}{1+\left(i \omega \tau_{1}\right)^{c_{1}}}-\frac{M_{2}}{1+\left(i \omega \tau_{2}\right)^{c_{2}}}\right),
$$

where $\sigma^{*}$ denotes the complex conductivity, $\omega$ is the angular frequency, and $\sigma_{\infty}$ denotes the instantaneous conductivity $(\mathrm{S} / \mathrm{m})$. In the following, the indices 1 and 2 refer to the lower and higher frequency dispersions, respectively. The instantaneous and DC conductivities can be decomposed into two contributions

$$
\begin{gathered}
\sigma_{\infty}=\sigma_{1}^{\infty}+\sigma_{2}^{\infty}, \\
\sigma_{0}=\sigma_{1}^{0}+\sigma_{2}^{0},
\end{gathered}
$$

plus a continuity condition on the conductivity given as

$$
\sigma_{1}^{\infty}=\sigma_{2}^{0}
$$

In these equations, $M_{1}$ and $M_{2}$ denote the chargeabilities associated with high- and low-frequency polarization components, $c_{1}$ and $c_{2}$ are the two Cole-Cole exponents (dimensionless), and $\tau_{1}$ and $\tau_{2}$ are the (relaxation) time constants (s). The two chargeabilities are defined as

$$
\begin{aligned}
& M_{1}=\frac{\sigma_{1}^{\infty}-\sigma_{1}^{0}}{\sigma_{\infty}}, \\
& M_{2}=\frac{\sigma_{2}^{\infty}-\sigma_{2}^{0}}{\sigma_{\infty}} .
\end{aligned}
$$

If the global chargeability is defined by $M=\left(\sigma_{\infty}-\sigma_{0}\right) / \sigma_{\infty}$, we have $M=M_{1}+M_{2}$ and because $0 \leq M \leq 1$, we have $0 \leq M_{1}+M_{2} \leq 1$. The above model is called the fitting model in the main text. The physical interpretation of the inverted Cole-Cole parameters should be done with caution. Indeed in the absence of metallic particles, the two Cole-Cole distributions correspond to the Clay and Maxwell-Wagner polarization. When pyrite is present, the two Cole-Cole distributions at low frequencies may correspond to the clay and pyrite polarization components. Therefore, great care should be exerted in comparing too quickly the fitting model parameters and the physical model developed in the main text.

The complex conductivity spectra are inverted using this double Cole-Cole model and the nonlinear iterative method proposed by Mosegaard and Tarantola (1995) based on a Monte Carlo Markov Chain sampling algorithm. The approach is described by Qi et al. (2018) and will not be repeated here. The seven model parameters are functions of $M_{1}, M_{2}, c_{1}, c_{2}, \tau_{1}, \tau_{2}$, and $\sigma_{\infty}$ (we use Jeffrey's parameters for the inversion to keep the following conditions satisfied: $0 \leq\left(M_{1}, M_{2}, c_{1}, c_{2}\right) \leq 1$ and $\sigma_{\infty}>0$; see Ghorbani et al., 2007). It follows that all the model parameters involved in equations A-1-A-3 can be retrieved. However, the high-frequency model parameters are determined with a high uncertainty if the frequency band is limited to $45 \mathrm{kHz}$ like in the present study. Finally, if we want then to retrieve the two conductivity contributions $\sigma_{1}^{\infty}$ and $\sigma_{2}^{\infty}$ from $M_{1}, M_{2}$, and $\sigma_{\infty}$, we need to go through additional algebraic manipulations given by

$$
\sigma_{1}^{\infty}=\frac{1}{2} \sigma_{\infty}\left(1-M_{2}\right)
$$

$$
\sigma_{2}^{\infty}=\frac{1}{2} \sigma_{\infty}\left(1+M_{2}\right)
$$

\section{APPENDIX B}

\section{SALINITY DEPENDENCE OF THE BACKGROUND CHARGEABILITY}

The polarization of clayey materials has been observed to depend on salinity (e.g., Weller et al., 2011). Our goal here is to determine the dependence of the quadrature conductivity of the background with the pore water conductivity. We start with the complexation reactions on the edge of illite 


$$
\begin{gathered}
>\mathrm{SH}^{0}+\mathrm{Na}^{+} \Leftrightarrow>\mathrm{S}^{-} \mathrm{Na}^{+}+\mathrm{H}^{+}, \\
>\mathrm{SH}^{0} \Leftrightarrow>\mathrm{S}^{-}+\mathrm{H}^{+},
\end{gathered}
$$

where $>\mathrm{S}$ refers the surface sites attached to the crystalline framework of illite and $\mathrm{H}^{0}$ denotes the protons. The weakly sorbed $\mathrm{Na}^{+}$is considered to be mobile in the Stern layer. There is also an electrical charge associated with isomorphic substitutions in the crystalline framework. The equilibrium constants are

$$
\begin{aligned}
K_{\mathrm{Na}} & =\frac{\Gamma_{\mathrm{SNa}}^{0}\left[\mathrm{H}^{+}\right]^{0}}{\Gamma_{\mathrm{SH}}^{0}\left[\mathrm{Na}^{+}\right]^{0}}, \\
K_{\mathrm{H}} & =\frac{\Gamma_{\mathrm{S}^{-}}^{0}\left[\mathrm{H}^{+}\right]^{0}}{\Gamma_{\mathrm{SH}}^{0}},
\end{aligned}
$$

where the $\left[\mathrm{H}^{+}\right]^{0}$ and $\left[\mathrm{Na}^{+}\right]^{0}$ correspond to the concentration of the protons and sodium counterions on the edge of the crystals of illite, respectively. The conservation equation of the surface species considering the sorption of sodium in the Stern layer of illite is

$$
\Gamma_{\mathrm{S}}^{0}=\Gamma_{\mathrm{SNa}}^{0}+\Gamma_{\mathrm{SH}}^{0}+\Gamma_{\mathrm{S}^{-}}^{0}+\Gamma_{\mathrm{X}}^{0},
$$

where $\Gamma_{\mathrm{S}}^{0}$ denotes the total surface site density $\left(\mathrm{m}^{-2}\right), \Gamma_{\mathrm{SNa}}^{0}, \Gamma_{\mathrm{S}^{-}}^{0}$, and $\Gamma_{\mathrm{SH}}^{0}$ represent the surface site density of the surface sites $>\mathrm{S}^{-} \mathrm{Na}^{+}$, $>\mathrm{S}^{-}$, and $>\mathrm{SH}^{0}$, respectively, and $\Gamma_{\mathrm{X}}^{0}$ represents the number of equivalent sites corresponding to isomorphic substitutions. If we use the associated equilibrium constant, the surface site density in the Stern layer can be expressed as (for details, see Niu et al., 2016)

$$
\Gamma_{\mathrm{SNa}}^{0}=\left(\Gamma_{\mathrm{S}}^{0}-\Gamma_{\mathrm{X}}\right) \frac{K_{\mathrm{Na}} C_{f}}{10^{-\mathrm{pH}}+K_{\mathrm{Na}} C_{f}+K_{H}} .
$$

We consider that $\Gamma_{\mathrm{S}}^{0}$ is related to the $\mathrm{CEC}$ by $e \Gamma_{\mathrm{S}}^{0}=\mathrm{CEC} / S_{\mathrm{sp}}$, where $S_{\mathrm{sp}}$ is the specific surface area. The normalized chargeability is given by

$$
\begin{gathered}
M_{n}^{b}=\frac{1}{F \phi} \rho_{g} \lambda e \Gamma_{\mathrm{SNa}}^{0} S_{\mathrm{Sp}}, \\
M_{n}^{b}=\frac{1}{F \phi} \rho_{g} \lambda e\left(\Gamma_{\mathrm{S}}^{0}-\Gamma_{\mathrm{X}}\right) \frac{K_{\mathrm{Na}} C_{f}}{10^{-\mathrm{pH}}+K_{\mathrm{Na}} C_{f}+K_{H}} S_{\mathrm{Sp}}, \\
M_{n}^{b}=\frac{1}{F \phi} \rho_{g} \lambda e\left(\Gamma_{\mathrm{S}}^{0}-\Gamma_{\mathrm{X}}\right) \frac{K_{\mathrm{Na}} \sigma_{w}}{e \beta K_{H}+K_{\mathrm{Na}} \sigma_{w}} S_{\mathrm{Sp}},
\end{gathered}
$$

where $e$ denotes the elementary charge and $\beta$ is the equivalent mobility in the expression of the pore water conductivity written as $\sigma_{w}=e \beta C_{f}$. The high-salinity normalized chargeability of the background is defined as

$$
M_{n}^{b, H S}=\frac{1}{F \phi} \rho_{g} \lambda e\left(\Gamma_{\mathrm{S}}^{0}-\Gamma_{\mathrm{X}}\right) S_{\mathrm{Sp}} .
$$

It corresponds to the maximum charge of the Stern layer that can be polarized through the application of an external electrical field. From equations B-9 and B-10, we have

$$
M_{n}^{b}=M_{n}^{b, H S} \frac{\sigma_{w}}{e \beta\left(K_{H} / K_{\mathrm{Na}}\right)+\sigma_{w}} .
$$

According to equation 14, the quadrature conductivity is proportional to the normalized chargeability according to

$$
\sigma^{\prime \prime} \approx-\frac{M_{n}}{\alpha}=\sigma_{b}^{\prime \prime H S} \frac{\sigma_{w}}{e \beta\left(K_{H} / K_{\mathrm{Na}}\right)+\sigma_{w}},
$$

where the high salinity quadrature conductivity is defined by

$$
\sigma_{b}^{\prime \prime H S}=M_{n}^{b, H S} / \alpha
$$

\section{REFERENCES}

Abdulsamad, F., N. Florsch, and C. Camerlynck, 2017, Spectral induced polarization in a sandy medium containing semiconductor materials: $\mathrm{Ex}-$ perimental results and numerical modelling of the polarization mechanism: Near Surface Geophysics, 15, 669-683, doi: 10.3997/1873-0604 .2017052.

Archie, G. E., 1942, The electrical resistivity log as an aid in determining some reservoir characteristics: Transactions of the AIME, 146, 54-62.

Armand, G., F. Leveau, C. Nussbaum, R. de La Vaissiere, A. Noiret, D. Jaeggi, P. Landrein, and C. Righini, 2014, Geometry and properties of the excavation-induced fractures at the Meuse/Haute-Marne URL drifts: Rock Mechanics and Rock Engineering, 47, 21-41.

Binley, A., S. S. Hubbard, J. A. Huisman, A. Revil, D. A. Robinson, K. Singha, and L. D. Slater, 2015, The emergence of hydrogeophysics for improved understanding of subsurface processes over multiple scales: Water Resources Research, 51, 3837-3866, doi: 10.1002/2015WR017016.

Bleil, D. F., 1948, Induced polarization: A method of geophysical prospecting: Ph.D. thesis, Michigan State College.

Bleil, D. F., 1953, Induced polarization: A method of geophysical prospecting: Geophysics, 18, 636-661, doi: 10.1190/1.1437917.

Ciesielski, H., T. Sterckeman, M. Santerne, and J. P. Willery, 1997, Determination of cation exchange capacity and exchangeable cations in soils by means of cobalt hexamine trichloride: Effects of experimental conditions: Agronomie, EDP Sciences, 17, 1-7.

Cole, K. S., and R. H. Cole, 1941, Dispersion and absorption in dielectrics: Journal of Chemical Physics, 9, 341-351, doi: 10.1063/1.1750906.

Cosenza, P., A. Ghorbani, N. Florsch, and A. Revil, 2007, Effects of drying on the low-frequency electrical properties of Tournemire argillites: Pure and Applied Geophysics, 164, 2043-2066.

Dias, C. A., 1972, Analytical model for a polarizable medium at radio and lower frequencies: Journal of Geophysical Research, 77, 4945-4956.

Dias, C. A., 2000, Developments in a model to describe low frequency electrical polarization of rocks: Geophysics, 65, 437-451, doi: 10.1190/1 .1444738 .

Ghorbani, A., C. Camerlynck, N. Florsch, P. Cosenza, A. Tabbagh, and A Revil, 2007, Bayesian inference of the Cole-Cole parameters from time and frequency-domain induced polarization: Geophysical Prospecting, 55, 589-605, doi: 10.1111/j.1365-2478.2007.00627.x.

Ghorbani, A., A. Revil, A. Coperey, A. Soueid Ahmed, S. Roque, M. J. Heap, H. Grandis, and F. Viveiros, 2018, Complex conductivity of volcanic rocks and the geophysical mapping of alteration in volcanoes: Journal of Volcanology and Geothermal Research, 357, 106-127, doi: 10 1016/j.jvolgeores.2018.04.014.

Hou, C.-Y., L. Feng, N. Seleznev, and D. E. Freed, 2018, Low frequency complex dielectric (conductivity) response of dilute clay suspensions: Modeling and experiments: Journal of Colloid and Interface Science, $\mathbf{5 2 5}, 62-75$

Johnson, I. M., 1984, Spectral induced polarization parameters as determined through time-domain measurements: Geophysics, 49, 1993-2003, doi: $10.1190 / 1.1441610$. 
Jougnot, D., A. Ghorbani, A. Revil, P. Leroy, and P. Cosenza, 2010, Spectral induced polarization of partially saturated clay-rocks: A mechanistic approach: Geophysical Journal International, 180, 210-224, doi: 10.1111/j .1365-246X.2009.04426.x.

Kaminski, V., and A. Viezzoli, 2017, Modeling induced polarization effects in helicopter time-domain electromagnetic data: Field case studies: Geophysics, 82, no. 2, B49-B61, doi: 10.1190/geo2016-0103.1.

Kiewer, M., 2000, Geoelektrische Charakterisierung von Tonformationen: M.Sc. thesis, Technical University Berlin.

Kratzer, T., and J. C. Macnae, 2012, Induced polarization in airborne EM: Geophysics, 77, no. 5, E317-E327, doi: 10.1190/geo2011-0492.1.

Kruschwitz, S., 2002, Detection and characterization of the disturbed rock zone in claystone with complex valued geoelectrics: M.Sc. thesis, Technical University Berlin.

Kruschwitz, S., and U. Yaramanci, 2004, Detection and characterization of the disturbed rock zone in claystone with the complex resistivity method: Journal of Applied Geophysics, 57, 63-79, doi: 10.1016/j.jappgeo.2004 .09 .003 .

Kwan, K., A. Prikhodko, J. M. Legault, G. Plastow, J. Xie, and K. Fisk, 2015, Airborne inductive induced polarization chargeability mapping of VTEM data: ASEG-PESA, Expanded Abstract.

Lesmes, D. P., and K. Frye, 2001, Influence of pore fluid chemistry on the complex conductivity and induced polarization responses of Berea sandstone: Journal of Geophysical Research, 106, 4079-4090.

Lima, A. L., and M. Sharma, 1990, A grain conductivity approach to shaly sandstones: Geophysics, 55, 1347-1356, doi: 10.1190/1.1442782.

Mao, D., and A. Revil, 2016, Induced polarization response of porous media with metallic particles - Part 3: A new approach to time-domain induced polarization tomography: Geophysics, 81, no. 4, D345-D357, doi: 10 .1190/geo2015-0283.1.

Mao, D., A. Revil, and J. Hinton, 2016, Induced polarization response of porous media with metallic particles - Part 4: Detection of metallic and non-metallic targets in time domain induced polarization tomography: Geophysics, 81, no. 4, D359-D375, doi: 10.1190/geo2015-0480.1.

Marshall, D. J., and T. R. Madden, 1959, Induced polarization, a study of its causes: Geophysics, 24, 790-816, doi: 10.1190/1.1438659.

Mosegaard, K., and A. Tarantola, 1995, Monte Carlo sampling of solutions to inverse problems: Journal of Geophysical Research, 100, 1243112447, doi: 10.1029/94JB03097.

Niu, Q., A. Revil, and M. Saidian, 2016, Salinity dependence of the complex surface conductivity of the Portland sandstone: Geophysics, 81, no. 2, D125-D140, doi: 10.1190/GEO2015-0426.1.

Okay, G., P. Cosenza, A. Ghorbani, C. Camerlynck, J. Cabrera, N. Florsch, and A. Revil, 2013, Characterization of macroscopic heterogeneities in clay-rocks using induced polarization: Field tests at the experimental underground research laboratory of Tournemire (Aveyron, France): Geophysical Prospecting, 61, 134-152, doi: 10.1111/j.1365-2478.2012 .01054.x.

Olhoeft, G. R., 1985, Low frequency electrical properties: Geophysics, $\mathbf{5 0}$ 2492-2503, doi: $10.1190 / 1.1441880$.

Pelton, W. H., S. H. Ward, P. G. Hallof, W. R. Sill, and P. H. Nelson, 1978, Mineral discrimination and removal of inductive coupling with multi-frequency IP: Geophysics, 43, 588-609, doi: 10.1190/1.1440839.

Qi, Y., A. Soueid Ahmed, A. Revil, A. Ghorbani, F. Abdulsamad, N. Florsch, and J. Bonnenfant, 2018, Induced polarization response of porous media with metallic particles - Part 7: Detection and quantification of buried slag heaps: Geophysics, 83, no. 5, E277-E291, doi: 10.1190/GEO2017-0760.1.

Razilov, I. A., and S. S. Dukhin, 1995, Simultaneous influence of concentration polarization of the diffuse layer and polarization of the Stern laye according to the mechanism of bound counterions at arbitrary magnitudes of the relaxation parameter: Colloid Journal, 57, 364-371 [translated from Kolloidnyi Zhurnal, 57, no. 3, 391-399].

Revil, A., G. Z. Abdel Aal, E. A. Atekwana, D. Mao, and N. Florsch, 2015b, Induced polarization response of porous media with metallic particles Part 2: Comparison with a broad database of experimental data: Geophysics, 80, no. 5, D539-D552, doi: 10.1190/GEO2014-0578.1.

Revil, A., A. Coperey, Y. Deng, A. Cerepi, and N. Seleznev, 2018b, Complex conductivity of tight sandstones: Geophysics, 83, no. 2, E55-E74, doi: 10.1190/GEO2017-0096.1.

Revil, A., A. Coperey, D. Mao, F. Abdulsamad, A. Ghorbani, M. Rossi, and D. Gasquet, 2018a, Induced polarization response of porous media with metallic particles - Part 8: Influence of temperature and salinity: Geophysics, 83, no. 6, E435-E456, doi: 10.1190/geo2018-0089.1.

Revil, A., A. Coperey, Z. Shao, N. Florsch, I. L. Fabricius, Y. Deng, J. R. Delsman, P. S. Pauw, M. Karaoulis, P. G. B. de Louw, E. S. van Baaren, W. Dabekaussen, A. Menkovic, and J. L. Gunnink, 2017c, Complex conductivity of soils: Water Resources Research, 53, 7121-7147, doi: 10 1002/2017WR020655.

Revil, A., and N. Florsch, 2010, Determination of permeability from spectral induced polarization data in granular media: Geophysical Journal International, 181, 1480-1498, doi: 10.1111/j.1365-246X.2010.04573.x.

Revil, A., N. Florsch, and D. Mao, 2015a, Induced polarization response of porous media with metallic particles - Part 1: A theory for disseminated semiconductors: Geophysics, 80, no. 5, D525-D538, doi: 10.1190/ GEO2014-0577.1.

Revil, A., D. Mao, Z. Shao, M. F. Sleevi, and D. Wang, 2017b, Induced polarization response of porous media with metallic particles - Part 6: The case of metals and semi-metals: Geophysics, 82, no. 2, E97-E110, doi: 10.1190/ geo2016-0389.1.

Revil, A., M. F. Sleevi, and D. Mao, 2017a, Induced polarization response of porous media with metallic particles - Part 5: Influence of the background polarization: Geophysics, 82, no. 2, E77-E96, doi: 10.1190/ geo2016-0388.1.

Rosen, L. A., J. C. Baygents, and D. A. Saville, 1993, The interpretation of dielectric response measurements on colloidal dispersions using the dynamic Stern layer model: The Journal of Chemical Physics, 98, 4183-4194

Rosen, L. A., and D. A. Saville, 1991, Dielectrical spectroscopy of colloidal dispersions: Comparisons between experiment and theory: Langmuir, 7, 36-42.

Shuey, R. T., and M. Johnson, 1973, On the phenomenology of electrical relaxation in rocks: Geophysics, 38, 37-48, doi: 10.1190/1.1440331.

Tarasov, A., and K. Titov, 2013, On the use of the Cole-Cole equations in spectral induced polarization: Geophysical Journal International, 195 , 352-356, doi: $10.1093 /$ gji/ggt251.

Vinegar, H. J., and M. H. Waxman, 1984, Induced polarization of shaly sands: Geophysics, 49, 1267-1287, doi: 10.1190/1.1441755.

Volckaert, G., X. Sillen, M. Van Geet, F. Bernier, J. C. Mayor, I. Goebel, P. Bluemling, B. Frieg, and K. Su, 2004, Similarities and differences in the behaviour of plastic and indurated clays, in P. Ruiz Fernandez, ed., Radioactive Waste Management - Community Policy and Research Initiatives: The 6th International Conference on the Management and Disposal of Radioactive Waste-Euradwaste '04, 955.

Wait, R. L., 1959, Over voltage research and geophysical application: Pergamon Press.

Waxman, M. H., and L. J. M. Smits, 1968, Electrical conductivities in oil bearing shaly sands: Society of Petroleum Engineers Journal, 8, 107-122.

Weller, A., K. Breede, L. Slater, and S. Nordsiek, 2011, Effect of changing water salinity on complex conductivity spectra of sandstones: Geophysics, 76, no. 5, F315-F327, doi: 10.1190/geo2011-0072.1.

Weller, A., L. Slater, and S. Nordsiek, 2013, On the relationship between induced polarization and surface conductivity: Implications for petrophysical interpretation of electrical measurements: Geophysics, 78, no. 5, D315-D325, doi: 10.1190/geo2013-0076.1.

Wong, J., 1979, An electrochemical model of the induced-polarization phenomenon in disseminated sulfide ores: Geophysics, 44, 1245-1265, doi: 10.1190/1.1441005.

Yaramanci, U., and M. Kiewer, 2004, Geoelectrical characterization of the disturbed rock zone in Opalinus clay (Mont Terri, Switzerland): Proceedings of 6th EEGS-ES Meeting, Expanded Abstracts, EL 14

Zhang, Z., A. Weller, S. Kruschwitz, and S. Nordsiek, 2019, Effect of evaporative drying on complex conductivity spectra of sandstones: Geophysics, 84, no. 1, MR61-MR72, doi: 10.1190/GEO2018-0054.1.

Zimmermann, E., J. Berwix, W. Glaas, H. Meier, H. M. Münch, and A. Kemna, 2007, ZEL-SIP04-V02: User manual: Forschungszentrum Julich $\mathrm{GmbH}$.

Zimmermann, E., A. Kemna, J. Berwix, W. Glaas, H. M. Münch, and J. A. Huisman, 2008, A high-accuracy impedance spectrometer for measuring sediments with low polarizability: Measurement Science and Technology, 19, 105603.

Zonge, K. L., and J. C. Wynn, 1975, Recent advances and applications in complex resistivity measurements: Geophysics, 40, 851-864, doi: 10 $.1190 / 1.1440572$. 